\title{
Nanodelivery of Natural Antioxidants: An Anti-aging Perspective
}

\author{
Alexander Vaiserman ${ }^{1 *}$, Alexander Koliada ${ }^{1}$, Alina Zayachkivska ${ }^{2}$ and Oleh Lushchak ${ }^{2 *}$ \\ ${ }^{1}$ Laboratory of Epigenetics, D.F. Chebotarev Institute of Gerontology, NAMS, Kyiv, Ukraine, ${ }^{2}$ Department of Biochemistry and \\ Biotechnology, Vasyl Stefanyk Precarpathian National University, Ivano-Frankivsk, Ukraine
}

\section{OPEN ACCESS}

Edited by:

Chiara Martinelli,

Istituto Italiano di Tecnologia, Italy

Reviewed by:

Jacqueline Nelisis Zanoni,

State University of Maringá, Brazil

Bruna Bellaver,

Federal University of Rio Grande do

Sul, Brazil

${ }^{*}$ Correspondence:

Alexander Vaiserman

vaiserman23@gmail.com

Oleh Lushchak

olehıpu.if.ua

Specialty section:

This article was submitted to

Nanobiotechnology,

a section of the journal

Frontiers in Bioengineering and

Biotechnology

Received: 22 October 2019 Accepted: 12 December 2019

Published: 10 January 2020

Citation:

Vaiserman A, Koliada A, Zayachkivska $A$ and Lushchak $O$ (2020) Nanodelivery of Natural Antioxidants: An

Anti-aging Perspective.

Front. Bioeng. Biotechnol. 7:447.

doi: 10.3389/fbioe.2019.00447
The aging process is known to be associated with heightened oxidative stress and related systemic inflammation. Therefore, antioxidant supplementation is regarded as a promising strategy to combat aging and associated pathological conditions. Food-grade antioxidants from plant-derived extracts are the most common ingredients of these supplements. Phyto-bioactive compounds such as curcumin, resveratrol, catechins, quercetin are among the most commonly applied natural compounds used as potential modulators of the free radical-induced cellular damages. The therapeutic potential of these compounds is, however, restricted by their low bioavailability related to poor solubility, stability, and absorbance in gastrointestinal tract. Recently, novel nanotechnology-based systems were developed for therapeutic delivery of natural antioxidants with improved bioavailability and, consequently, efficacy in clinical practice. Such systems have provided many benefits in preclinical research over the conventional preparations, including superior solubility and stability, extended half-life, improved epithelium permeability and bioavailability, enhanced tissue targeting, and minimized side effects. The present review summarizes recent developments in nanodelivery of natural antioxidants and its application to combat pathological conditions associated with oxidative stress.

Keywords: age-associated disorders, nano-antioxidants, phytochemicals, oxidative stress, bioavailability, nanodelivery, anti-inflammatory properties

\section{INTRODUCTION}

Population aging is becoming an increasingly important social and economic challenge for modern society. This is because the rising human life expectancy is generally not accompanied by the same increase in healthspan. The burden of age-related disorders has been steadily increasing over the past decades in most developed countries (Seals et al., 2016; Yabluchanskiy et al., 2018). Therefore, the development of treatment modalities specifically targeting aging pathways becomes a vital task of medical research and healthcare industry now (Vaiserman and Marotta, 2016; Vaiserman and Lushchak, 2017; Myers and Lithgow, 2019). Development and implementation of such therapeutic options is a main goal of a new research platform, translational geroscience, aimed at optimizing and preserving physical and psychosocial functioning throughout the human lifespan and compress disabilities and morbidity into a shorter period of late-life to achieve optimal longevity (Seals and Melov, 2014; Seals et al., 2016). A progress in this rapidly developing field is certainly depended on unraveling the mechanistic basis of aging process (Crimmins, 2015). Over three last decades, there was an unprecedented growth in our understanding of the basic pathways underlying aging (Campisi et al., 2019). The aging-associated chronic oxidative stress and 
related systemic inflammation are undoubtedly among pathways most significantly contributing to cellular senescence and aging (Liguori et al., 2018). Damages in vital biomolecules, including lipids, proteins (enzymes) or nucleic acids, caused by reactive oxygen species (ROS) and other free radicals generated in mitochondria through metabolic processes are considered to be among the primary drivers of aging process (Lushchak et al., 2014; Santos et al., 2018). ROS have been repeatedly shown to be implicated in basic aging-associated processes such as telomere attrition (Barnes et al., 2019), autophagy (Pajares et al., 2018), and exhaustion of the stem-cell population (Chen et al., 2017). The roles of oxidative stress and related inflammation are also becoming increasingly evident in the pathogenesis of most agerelated pathological conditions including atherosclerosis (Yang et al., 2017), insulin resistance (Yaribeygi et al., 2019), and various cardio-metabolic and neurodegenerative diseases (Verdile et al., 2015; Garaschuk et al., 2018; Cenini et al., 2019). Based on these theoretical considerations, reducing the oxidative stress level by dietary supplementation with antioxidants known to neutralize free radicals by electron donation is recognized by many authors as a promising interventional strategy to delay or prevent agerelated pathological conditions.

The therapeutic potential of dietary antioxidants is, however, restricted in most cases by their low bioavailability related to their poor solubility and stability in gastrointestinal fluids. Currently, innovative nanotechnology-based applications aimed at improving the oral bioavailability, and, accordingly, therapeutic effectiveness of phytochemicals and other natural antioxidants are emerging. The aim of this review is to provide information about recent advances in the application of phytoantioxidant-based nanodelivery systems to combat the aging-related oxidative stress and associated pathological conditions.

\section{Synthetic Antioxidants: Health Benefits and Hazards}

Chronic oxidative stress-associated ROS overproduction is known to lead to damage of vital biomolecules and abnormal expression of various genes, including those involved in aging pathways (Lushchak, 2014; Tan et al., 2018). Therefore, it is considered to be one of the most important contributing factors in onset and progression of many aging-related pathological conditions. Under normal physiological conditions, ROS levels are strongly controlled in the cell by endogenous antioxidant enzymes, such as superoxide dismutase (SOD), glutathione (GSH) peroxidase, and catalase (CAT), and by exogenous antioxidants, such as vitamins, minerals, and polyphenols (Rahal et al., 2014). Under age-related pathological conditions, abnormally large ROS concentrations can damage a wide variety of biomolecules, thereby resulting in permanently disrupted profiles of gene expression and signal transduction, thus accelerating aging (Tan et al., 2018). Chronic oxidative stress condition also leads to an enhanced level of nonenzymatic, covalent attachment of glucose molecules to proteins, resulting in an elevated generation of advanced glycation end products (AGEs), known to be substantially contributed to aging and age-associated disorders (Kim C. S. et al., 2017; Chaudhuri et al., 2018; Fournet et al., 2018). In addition, the glycation of antioxidant enzymes such as copper-zinc SOD and GSH reductase may impair the organism's endogenous antioxidant defense system (Fournet et al., 2018). Chronic oxidative stress may also result in the accelerated telomere attrition with age. Telomeres are nucleotide repeated sequences of eukaryotic linear chromosomes that cap the chromosome ends to protect from undesirable enzymatic activities. In absence of specific enzymatic activity of telomerase, telomeres shorten with every cell division, being thereby substantially involved in aging processes (Hayashi, 2018; Liu et al., 2019). Emerging evidence, however, indicates the age-related telomere shortening depends not only on the number of divisions that cells have undergone, but also on the level of oxidative stress (Koliada et al., 2015). Taken together, these considerations indicate that oxidative stress may significantly contribute to aging and associated diseases, suggesting that counteracting oxidative stress may be an effective way to slow down or delay aging (for reviews, see Liguori et al., 2018; Forni et al., 2019; Zuo et al., 2019).

Thus, supplementation with dietary antioxidants is traditionally considered by many scholars and medical practitioners as a reasonable intervention strategy to delay or prevent age-related pathological conditions. The research findings on this topic are, however, quite controversial. On the one hand, supplementation with dietary antioxidants indeed caused beneficial effects on aging and longevity in various animal models (Sadowska-Bartosz and Bartosz, 2014). The popularization of these findings has led to the situation where more than half of adult residents of high-income countries regularly consume dietary antioxidants with hope to slow aging and extend healthspan (Bjelakovic et al., 2014). On the other hand, many randomized controlled trials of antioxidant supplements in humans have failed to improve health and prevent cardiovascular diseases and other agerelated pathological conditions (Myung et al., 2013; Gruber and Halliwell, 2017). Furthermore, synthetic antioxidants such as vitamins were found to be potentially dangerous, and some epidemiological findings indicate that regular intake of $\beta$-carotene, vitamin $\mathrm{A}$ and vitamin $\mathrm{E}$ may even increase mortality, especially in well-nourished populations (Bjelakovic et al., 2014). The discrepancy between results obtained in animal models and clinical trials, which is generally referred to as an "antioxidant paradox" (Halliwell, 2000), may probably be due to the dual roles of antioxidants in ROS production. Indeed, dietary antioxidants can act not only as ROS scavengers; they may also be easily oxidized and act as pro-oxidants to induce damages in vital biomolecules when present in a large concentration (Milisav et al., 2018). Moreover, accumulating evidence suggests that ROS play crucial roles as important second messengers involved in many vital processes, including intracellular signaling, cell survival, proliferation, differentiation and apoptosis, and also immune and stress responses (Schieber and Chandel, 2014; Pizzino et al., 2017; Bardaweel et al., 2018; Milkovic et al., 2019; see also Figure 1 for illustration). The considerations above imply that targeting ROS-related disorders 


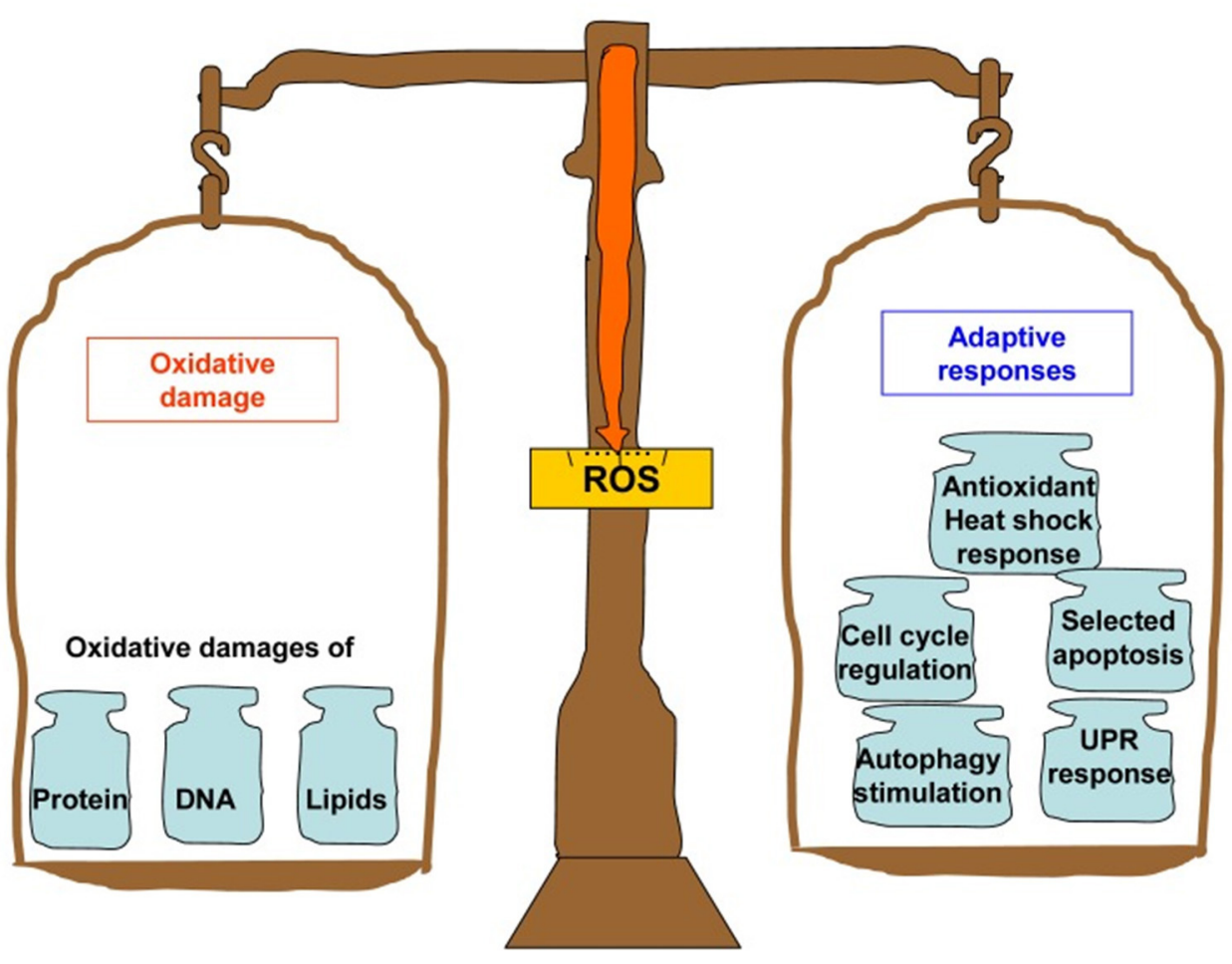

FIGURE 1 | Summary of the bifurcated effects that can be induced by ROS. On the one hand, ROS induces the oxidative damage to proteins, DNA and lipids. On the other hand, they also trigger the organism's adaptive responses including antioxidant and heat shock responses, fatty acid deacylation-reacylation, cell cycle regulation, DNA repair and apoptosis, unfolded protein responses, and autophagy stimulation. The figure and its legend are reproduced from the open-access article by Mao and Franke (2013) distributed under the terms of the Creative Commons Attribution License with permission from the authors.

by pharmacologically-synthesized antioxidant drugs is extremely complex and difficult task.

\section{Natural Antioxidants}

Disappointing outcomes of clinical trials with synthetic antioxidants have resulted in doubts regarding the appropriateness of their use to combat atherosclerosis and other ROS-mediated degenerative diseases (Toledo-Ibelles and Mas-Oliva, 2018). Therefore, dietary supplementation with natural antioxidants derived predominantly from plant sources, such as polyphenols and carotenoids, has been proposed as a reasonable alternative to synthetic antioxidant intake (Xu et al., 2017; Serino and Salazar, 2018; Forni et al., 2019; Neha et al., 2019). Phytochemicals are secondary metabolites produced by plants to protect them from environmental stresses such as microbial infections, environmental pollutant exposures, temperature changes, and drought (Leonov et al., 2015). Due to such properties, they are considered to be promising candidates for developing healthspan- and lifespan-promoting interventions (Leonov et al., 2015). The efficiency of phytochemicals such as resveratrol, curcumin, catechins, genistein, and quercetin in counteracting various pathological conditions mediated by aging-related oxidative stress and associated chronic inflammation has been repeatedly reported (Corrêa et al., 2018; Martel et al., 2019). Chemical structures of the most commonly used phytotherapeutic compounds with potent antioxidant properties are presented in Figure 2 below.

One important problem is, however, that therapeutic potential of orally administered phytochemicals is substantially restricted because of their low bioavailability than is primarily attributed to their poor water solubility and intestinal permeability (Aqil et al., 2013; Khadka et al., 2014). In particular, the oral bioavailability was found to be about 1-2\% for all quercetin (Kawabata et al., 2015; Li et al., 2016), resveratrol (Walle, 2011) and curcumin (Asai and Miyazawa, 2000; Yang et al., 2007), while for the epigallocatechin-3-gallate (EGCG) it is estimated to be about 0.1 $0.3 \%$ only (Pervin et al., 2019). Therefore, novel biotechnological approaches are being actively developed by now to enhance the oral bioavailability and bioactivity of these substances. Recently, innovative nanotechnological applications have been developed to overcome this issue by improving the bioactivity of phytochemicals following oral administration.

\section{Therapeutic Advantages of Nanodelivery Systems}

Among the most important features of orally administered nanomedicines, it is their capability to overcome the chemical and physical barriers in the gut such as the acidic $\mathrm{pH}$ of the stomach, intestinal mucosal lining and selectively permeable membranes of enterocytes (Moss et al., 2018). Physico-chemical 
Polymeric nanoparticle

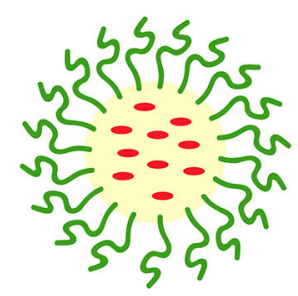

Dendrimer

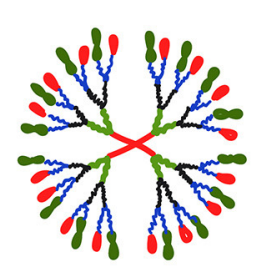

Liposome

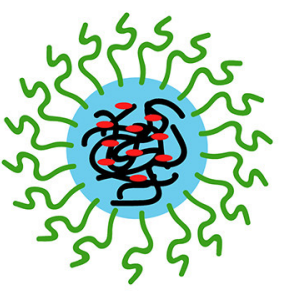

Nanoemulsion

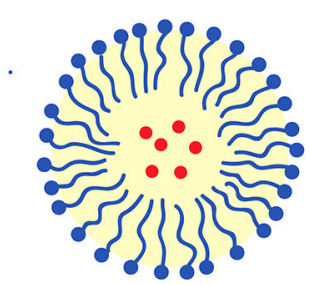

Micelle

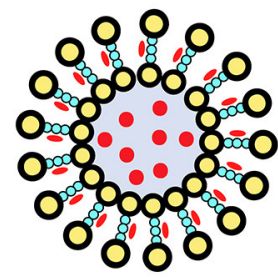

Nanotube

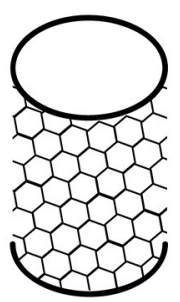

FIGURE 2 | Chemical structures of the most commonly used phytoantioxidants.

characteristics of nanoparticles such as their metabolism, absorption, distribution and excretion depend on their size, hydrophobicity and charge. Size is an important parameter of nanoparticle that determines its pharmacokinetics, entry into the cell, and interaction with the immune system (Hoshyar et al., 2016). Surface properties of nanoparticles determine their hydrophilicity or hydrophobicity and also various biological responses, including cellular uptake, interactions with plasma proteins, particle removal as well as immune responses (Ajdary et al., 2018). Surface charge is also among the most important properties of nanoparticle substantially determining its cellular absorption and cytotoxicity (Fröhlich, 2012). Due to their properties, nanoparticles may protect loaded bioactive substances from degradation throughout the gastrointestinal digestion and cellular metabolism. Nanocarried bioactive agents are ultimately released in the gastrointestinal tract, in the circulatory system or in various tissues (Martínez-Ballesta et al., 2018). Their subsequent biological fate depends on their own chemical and physical properties and also on the site of release. Importantly, the location of bioactive release can be driven by using nanomaterials with certain surface chemistry; it makes possible the release of such therapeutics in particular tissues and body sites (Patra et al., 2018).

The nanostructures can act by either active or passive therapeutic targeting (Kydd et al., 2017). Following the passive nanodelivery mode, the loaded therapeutic agent is released by the erosion or diffusion of the delivering nanovector. The active delivery mode allows the controlled release of transported biomolecules at the targeted body sites. In this delivery mode, certain RNAs, proteins, lipids, carbohydrates, and small metabolite molecules are used as biomarkers to reach particular target sites (Conte et al., 2017). Selective targeting to specific tissues or body sites also becomes possible in this therapeutic modality by incorporating specific stimuliresponsive components which can be triggered by particular stimuli such as electric or magnetic field, light, $\mathrm{pH}$, heating, ultrasound, and also by contact with concentrated ionic solutions or certain enzymes ( $\mathrm{Gu}$ et al., 2018). Moreover, there exists a possibility to modify the physical surface properties of metallic nanoparticles, such as silver, gold, and iron oxide nanoparticles, so that they act as drug carriers by the active delivery mode (Kong et al., 2017). The use of organic nanocarriers is, however, considered to be more preferred because of their physicochemical properties can be more finely tuned by modifying their chemical composition, shape, size, structural morphology, and characteristics of surface (Conte et al., 2017). The efficiency of nanodelivery of natural therapeutic agents is also dependent on their molecular weight. Increase of the molecular weight generally results in a decrease in efficiency of delivery of loaded compounds resulting in their lower bioavailability (Ganesan et al., 2018b). Different therapeutic nanodelivery systems can provide various health benefits depending on their properties, the features of loaded agents and also on desired therapeutic applications (Gupta and Xie, 2018; Rizvi and Saleh, 2018). In particular, natural compound-loaded nanoparticles provide many benefits over conventional formulations in terms of therapeutic potential. These benefits include improved epithelium permeability, enhanced stability, extended halflife, increased solubility and bioavailability, improved tissue targeting as well as minimized side effects (Date et al., 2016; 
Kermanizadeh et al., 2018). The nanotechnology-based systems are increasingly applied now to prevent and cure aging-associated pathological conditions, including neurodegenerative disorders such as Alzheimer's and Parkinson's diseases (Poovaiah et al., 2018; Ramanathan et al., 2018), cardiovascular diseases (Li et al., 2018; Taneja et al., 2019), obesity and type 2 diabetes (Bahadori et al., 2019; Tsou et al., 2019), and also tumors (Qiao et al., 2019).

\section{Therapeutic Nanodelivery Systems}

The oral administration route is commonly considered as the most accepted way for drug delivery due to simplicity of administration, pain avoidance, patient compliance, and easy self-administration (Anselmo and Mitragotri, 2014). However, since the efficiency of oral drug delivery may be substantially reduced due to chemical and enzymatic barriers and also poor solubility in the gastrointestinal tract, the oral delivery of therapeutic compounds loaded into nanocarriers has become a subject of comprehensive investigation over the last years (Kermanizadeh et al., 2018). Delivery by nanocarriers generally may have varied therapeutic advantages. These advantages include, among others, an increased half-life, extended circulation time, enhanced mean residence time, and improved pharmacokinetic clearance of these agents from the body (Ravindran et al., 2018). Currently, many nanosized delivery systems intended for oral administration of phytotherapeutics have reached the clinical trial stage and are increasingly applied in clinical practice (Hajialyani et al., 2018). One important challenge in this research is developing novel multifunctional nanomaterials possessing properties allowing them to transfer particular therapeutics across various biological barriers and able to target specific cell types, tissues and organs in the body. Successful nanodelivery systems are characterized by optimal features for loading and release of therapeutic agent, long storage life, as well as high therapeutic efficacy with no or minimized side effects (Bilia et al., 2017; Piazzini et al., 2018). Among these nanodelivery systems, there are both solid (nanocrystals, lipid and polymeric nanoparticles) and liquid (including nanoliposomes, nanoemulsions, and nanopolymersomes) ones (Borel and Sabliov, 2014; Ganesan et al., 2018a). These systems are described in details in the subsequent sections.

\section{Nanoemulsions}

Nanoemulsions include mixtures of immiscible liquids, such as e.g., water and oil (Jaiswal et al., 2015). Such nanosystems are generally prepared by either chemical or mechanical methods. Chemical methods result in spontaneous formation of emulsion droplets due to hydrophobic effects of lipophilic molecules which take place in the presence of emulsifiers. Mechanical methods include high-energy processes by which large emulsion droplets may be broken down into the smaller ones by various mechanical operations. The basic difference among nanoemulsions and conventional emulsions lies in the shapes and sizes of particles dispersed in a suspension. The droplet sizes in nanoemulsions ordinarily fall in the range of $20-200 \mathrm{~nm}$.

\section{Nanoliposomes}

Nanoliposomes represent nanosized self-assembled vesicles which consist of phospholipid bilayers entrapping one or more aquatic compartments (Chan and Král, 2018). There are fine oil-in-water $(\mathrm{o} / \mathrm{w})$ dispersions with droplet sizes ranging between 50 and $450 \mathrm{~nm}$ (Bozzuto and Molinari, 2015). Such nanodelivery systems may be produced by layer-by-layer electrostatic deposition technique. In this technique, charged polymers are added to a solution containing a charged template structure (Chun et al., 2013). Such template structures may be, e.g., emulsion droplets stabilized by ionic emulsifiers, liposomes composed of charged polar lipids, or hydrogel particles composed of charged biopolymers. The other method to produce nanoliposomes is the gentle hydration (the process of hydration of dried lipid films with an aqueous solution).

\section{Nanopolymersomes}

Nanopolymersomes (NPS) are artificial vesicles with sizes from tens of $\mathrm{nm}$ up to $1 \mu \mathrm{m}$ which enclose aqueous cavities, resulting from self-assembly of amphiphilic copolymers (Zhang and Zhang, 2017). The tunable properties of NPS allow to adjust them for different biomedical applications, e.g. as drug delivery vehicles or as artificial organelles (Pippa et al., 2016; Tuguntaev et al., 2016). They are synthesized by methods similar to those applied to producing polymeric nanoparticles (see below). The overall properties of NPS, including drug encapsulation and release capability, may be effectively tuned by using different biodegradable and/or stimuli-responsive block copolymers (Zhang and Zhang, 2017). Owing to their tunable properties, NPS are capable to encapsulate hydrophobic and hydrophilic molecules either in a membrane bilayer or in an aqueous core, respectively. Their advantages, in comparison with nanolipid carriers, include enhanced stability and versatility, and also controlled release (Rastogi et al., 2009). Due to these properties, NPS are considered to be potentially attractive drug carriers in many clinical applications.

\section{Nanocrystals}

Nanocrystals are sub-micron (usually from 10 to $800 \mathrm{~nm}$ ) colloidal dispersion systems consisting of pure (carrier-free) drug nanoparticles (Gigliobianco et al., 2018). They can be produced with either mechanical or chemical methods. The basic advantage of such nanosystems is reducing the particle size to nanoscale range, resulting in an increase of the particle surface area which is in contact with the dissolution medium (Singh and Lillard, 2009). Therefore, nanocrystal formulations are believed to have potential therapeutic benefits compared to the conventionally used pharmaceutical formulations. Among others, these benefits include improved saturation solubility and dissolution rate, and also high drug loading (Zhou et al., 2017).

\section{Solid Lipid Nanoparticles}

Solid lipid nanoparticles (SLP) are similar to nanoemulsions, except that they contain lipids in solid phase. These are submicron colloidal nanocarriers ranging from 50 to $1,000 \mathrm{~nm}$ consisting of physiological lipids dispersed either in water or 
in aqueous surfactant solutions (Mishra et al., 2018; da Silva Santos et al., 2019). SLP are produced by high-energy methods such as microfluidization (high-pressure homogenization) and ultrasonication (a process that uses high-frequency sound energy to break apart particle agglomerates by expansion, cavitation and implosion of bubbles) (Mehnert and Mäder, 2001). The advantages of such nanoparticles include small size, large surface area, high drug loading efficiency, and the interaction of phases at the interface (Mishra et al., 2018). This type of nanocarriers was developed to overcome limitations of colloidal nanocarriers such as emulsions, liposomes, and polymeric nanoparticles since they can provide benefits such as targeted drug delivery and a good release profile (Naseri et al., 2015). The loading of therapeutic agents in such nanoparticles may occur in two ways: they can be either integrated in the core matrix or attached on the surface of nanoparticle (Lin et al., 2017). One important advantage of solid lipid nanoparticles is that they provide an option to entrap lipophilic molecules in stable particles without applying organic solvents. Such nanoparticles provide multiple therapeutic advantages due to their unique size-dependent properties and capacity to incorporate drugs. These advantages include feasibility for largescale production, possibility of incorporating both lipophilic and hydrophilic drugs, high bioavailability of loaded drugs and low toxicity (Bayón-Cordero et al., 2019).

\section{Polymeric Nanoparticles}

Polymeric nanoparticles include solid colloidal nanoparticles sized from 10 to $1,000 \mathrm{~nm}$ consisting of either synthetic or natural polymers (Crucho and Barros, 2017; Khan et al., 2017). These nanostructures are believed to have improved performance in energy storage compared to the bulk conducting polymers due to their high electrical conductivity, high electrochemical activity, large surface area, and short path lengths for the transport of ions (Pan et al., 2010). The methods for preparing polymer nanoparticles include nanoprecipitation, solvent evaporation, salting-out, dialysis, and supercritical fluid technology. They may also be directly synthesized by the polymerization of monomers by using techniques such as mini- and microemulsion, interfacial polymerization, and controlled/"living" polymerization methods (Krishnamoorthy and Mahalingam, 2015; Heinz et al., 2017). Surface modification of the polymeric nanoparticles is achieved via self-assembly of block copolymers containing segments that form the core of the polymer nanoparticle and segments that form the outer surfactant shell upon assembly (Heinz et al., 2017). Drug-loaded polymer nanoparticle synthesis is carried out using biodegradable and biocompatible polymers or copolymers, in which therapeutic agents may be encapsulated or entrapped within the carriers or be physically adsorbed on or chemically linked to the nanoparticle surfaces. Polymeric nanoparticles generally fall into two major subtypes, i.e., nanospheres where loaded agents are uniformly dispersed and nanocapsules where therapeuticals are confined to the inner aqueous or oily cavities surrounded by polymeric membranes (Grottkau et al., 2013). The attractive capabilities of these nanostructures include water solubility, small size, storage stability, biodegradability, long shelf life, and non-toxicity (Kamaly et al., 2016). Owing to their physico-chemical characteristics, polymeric nanoparticles also demonstrate good encapsulation efficiency, and also improved solubility and stability of hydrophobic drugs. These properties allow to minimize toxicity of loaded drugs, permitting a controlled release at targeted sites of the body at relatively low doses (Kamaly et al., 2016).

Some of the most widely used solid and liquid nanodelivery systems are schematically presented in Figure 3.<smiles>O=C(O[C@H]1Cc2c(O)cc(O)cc2O[C@H]1c1cc(O)c(O)c(O)c1)c1cc(O)c(O)c(O)c1</smiles>

EGCG<smiles>O=c1c(OS(=O)(=O)O)c(-c2ccc(O)c(O)c2)oc2cc(O)cc(O)c12</smiles>

Quercetin<smiles>Oc1ccc(/C=C/c2cc(O)cc(O)c2)cc1</smiles>

Resveratrol<smiles>COc1cc(/C=C/C(=O)CC(=O)/C=C/c2ccc(O)c(OC)c2)ccc1O</smiles>

Curcumin<smiles>O=c1c(-c2ccc(O)cc2)coc2cc(O)cc(O)c12</smiles>

Genistein

FIGURE 3 | Graphical representations of the most common types of nanocomposites. 


\section{Metallic Nanoparticles}

Metallic nanoparticles with diameters ranging from 1 to $100 \mathrm{~nm}$ such as silver, gold, copper, magnesium, aluminum, titanium, and zinc ones are increasingly being applied for either passive or active drug delivery in different biomedical applications. An important point is that metallic nanoparticles can be synthesized and modified with various chemical functional groups which allow them to be conjugated with different drugs of interest to target certain cells and tissues (Mody et al., 2010). Their obvious advantages in clinical applications include relatively simple synthesis, easy chemical modification, biocompatibility, and tunable biophysical properties (Lushchak et al., 2018).

\section{Nano-Antioxidants}

One of major factors limiting clinical use of most nanoparticle formulations is their capability to induce oxidative stress at cellular level (Fu et al., 2014; Zuberek and Grzelak, 2018). One important point in this regard, however, is that levels of generated ROS are dependent on the nanoparticle concentration to which the cell is exposed. Different nanomaterials may influence cellular redox environment by either stimulating or inhibiting ROS production, and a biphasic dose-response relationship characterized by a low-dose stimulation and a high-dose inhibition (hormetic response) could likely play a crucial role in redox-modulating effects induced by nanoparticles (Iavicoli et al., 2018). The exposure to high nanoparticle concentrations usually results in excess ROS generation and overloading of endogenous antioxidant systems, eventually causing cytotoxicity, and inflammation (Nel et al., 2006). Determination of maximal admissible doses is considered therefore to be critical to avoid adverse health outcomes. Accumulating evidence, however, suggests that low-level nanoparticle exposures may unexpectedly enhance antioxidant defense ability and depress oxidative stress (Abdal Dayem et al., 2017). Some nanomaterials have been found to be able to exhibit enzyme-like antioxidant properties by being capable to scavenge ROS and other free radicals, thereby reducing oxidative injury (Lushchak et al., 2018). Such nanomaterials are generally referred to as "nano-antioxidants" (Watal et al., 2013; Du et al., 2014; Sandhir et al., 2015). Nano-antioxidants include non-organic nanoparticles such as metallic nanoparticles with intrinsic antioxidant properties (Lushchak et al., 2018) as well as nanoparticles functionalized with antioxidant enzymes or natural antioxidants (Sandhir et al., 2015). The antioxidant potential of nanocarriers loaded with phytotherapeutic agents is described in more detail in the following subsections.

\section{Nano-Phytoantioxidants: New Promise in Anti-aging Research}

Many nanodelivery systems loaded with plant-based bioactive compounds have been demonstrated to be efficacious in modulating oxidative stress and related chronic inflammation which mediates most aging-associated disorders. Results from studies reporting antioxidant effects of such nanodelivery systems are discussed in subsections below.

\section{Nano-Resveratrol}

Resveratrol (3,5,4'-trans-trihydroxystilbene) is a polyphenol compound found in grapes skin and seeds, and, in lesser amounts, in several other plant sources (Salehi et al., 2018). In plants, it acts as a phytoalexin, protecting them from pathogens such as fungi and bacteria. In a number of animal models, potent antioxidant properties of resveratrol have been consistently reported. The antioxidant capacity of this polyphenolic compound strongly depends on the redox properties of phenolic hydroxyl groups and the potential for electron delocalization across its chemical structure (Sedlak et al., 2018). Resveratrol has three hydroxyl groups (see Figure 2 for illustration) known to play crucial roles in ROS scavenging. Moreover, these hydroxyl groups help to chelate metal ions, which is an essential feature in the prevention of ROS production (Gülçin, 2010). Furthermore, the cellular defense might be achieved by ability of resveratrol to act not only as a direct antioxidant, but also as an indirect manner, as an endogenous antioxidant system inducer (Salehi et al., 2018). Resveratrol can trigger Nrf2 transcription factor known to regulate variety of antioxidant enzymes (Lushchak, 2011; Smith et al., 2016). In addition, the antioxidant properties of this polyphenolic compound might be attributable to its effects as a gene regulator. Particularly, it was shown that down-regulating the expression of NADPH oxidase may inhibit ROS production (Xia et al., 2017). Resveratrol can also reduce mitochondrial superoxide production by stimulating mitochondrial biogenesis, prevent superoxide generation from uncoupled endothelial nitric oxide synthase by up-regulating the tetrahydrobiopterin-synthesizing enzyme GTP cyclohydrolase I, and also increase the expression of different antioxidant enzymes (Xia et al., 2017).

Antioxidant properties of resveratrol are believed to be responsible for most health-promoting effects of this substance (Carrizzo et al., 2013). Moreover, its anti-inflammatory, cardioprotective, neuroprotective, and also anti-cancer properties have also been repeatedly reported. Therefore, it is regarded as one of the most promising anti-aging natural compounds now (Wahl et al., 2018). Its anti-aging effects are believed to be attributed to capacity to activate mammalian silent information regulator 1 (SIRT1) and modulate activity of certain important regulatory proteins known to be crucially implicated in aging processes, including Akt/protein kinase $\mathrm{B}$, peroxisome proliferator-activated receptor coactivator- $1 \alpha$ (PGC-1 $\alpha)$, NF- $\kappa \beta$ and FoxO, and also cellular processes such as apoptosis, angiogenesis, mitochondrial biogenesis, lipid metabolism and gluconeogenesis (Camins et al., 2009; Pannu and Bhatnagar, 2019). Many of these activities are similar to those found in calorie restriction research, thereby demonstrating the potential of resveratrol as a calorie restriction mimetic (Li J. et al., 2017). Its effectiveness and safety have been welldocumented in many animal models and in clinical trials. The therapeutic potential of resveratrol has been reported for various aging-associated pathological conditions such as metabolic syndrome, obesity, type 2 diabetes, cardiovascular disorders, hypertension, stroke, chronic kidney and inflammatory 
diseases, dementia and also breast, and colorectal cancers (Berman et al., 2017; Ramírez-Garza et al., 2018; Singh et al., 2019).

The therapeutic applicability of resveratrol is, however, substantially restricted through its extensive hepatic and presystemic metabolism (Pangeni et al., 2014; Smoliga and Blanchard, 2014). Moreover, the water solubility of this phytochemical is very low, thereby causing poor absorption by oral administration (Chauhan, 2015). Considering this, many preclinical and clinical trials are in progress now to create structurally modified derivatives of resveratrol having higher bioavailability upon ingestion (Popat et al., 2013). One example is a micronized liquid formulation of trans-resveratrol, SRT501, which demonstrated roughly five times higher bioavailability compared to non-micronized compound (Elliot and Jirousek, 2008). In several clinical trials, however, SRT501 was not well-tolerated and resulted in side effects, including vomiting and diarrhea, which caused dehydration and renal failure in some patients (Popat et al., 2013). It prompted the search for nanomaterials acting similarly to SRT501, but without its side effects (Smoliga et al., 2012). Recently, some such nanosized resveratrol-loaded formulations have been investigated for their potential clinical utility. The bioavailability of orally delivered trans-resveratrol loaded in lipid-core nanocapsules was found to be two times higher than that of the free trans-resveratrol in brain, kidney and liver of male Wistar rats (Frozza et al., 2010). Nanodelivery also resulted in improved gastrointestinal safety in this model. The bioavailability of the folate-conjugated human serum albumin-encapsulated resveratrol nanoparticles was also shown to be 6-fold higher compared to native resveratrol following the intravenous administration (Lian et al., 2019).

Several studies have demonstrated antioxidant properties of nano-encapsulated resveratrol. For instance, in the study by Chen et al. (2015), resveratrol nano-encapsulated in self-microemulsified drug delivery system exhibited higher antioxidant capability and reduced toxicity compared to free resveratrol. Resveratrol loaded in nanoliposome carriers (size from 103 to $134 \mathrm{~nm}$ ) also exhibited more pronounced radical scavenging effect when compared to pure resveratrol (Vanaja et al., 2013). High ROS scavenging efficiency was also demonstrated for the vitamin E-loaded resveratrol nanoemulsion (an average globule diameter of about $100 \mathrm{~nm}$ ) in patients with Parkinson's disease (Pangeni et al., 2014). The activities of endogenous antioxidant enzymes, including SOD, and GSH lelels were shown to be significantly higher, and levels of malondialdehyde was significantly lower in the resveratrol nanoemulsion-administered group. Resveratrol loaded in zein nanoparticles with bovine serum albumin-caffeic acid conjugate (particle size from 206 to $217 \mathrm{~nm}$ ) was demonstrated to exert significantly higher cellular antioxidant activity than resveratrol alone (Fan et al., 2018a). Anti-inflammatory abilities of resveratrol-loaded nanoparticles, such as galactosylated poly(lactic-co-glycolic acid) nanoparticles, have been also reported (Siu et al., 2018).

\section{Nano-Curcumin}

Curcumin [1,7-bis(4-hydroxy-3-methoxyphenyl)-1,6-heptadiene3,5-dione] is a polyphenol extracted from rhizome of the turmeric plant, Curcuma longa. It is traditionally used in Asian countries as herbal treatment (Hewlings and Kalman, 2017). This compound has three chemical components in its structure, including one diketone moiety and two phenolic groups (Figure 2). The active functional groups of curcumin may undergo oxidation via electron transfer and hydrogen abstraction processes (Priyadarsini, 2014). In particular, the antioxidant activity of curcumin is determined by methylenic hydrogen and o-methoxy phenolic groups. Moreover, the $\beta$ diketone groups can chelate ions transition metals; some of these metal complexes exhibit antioxidant enzyme-mimetic activities (Priyadarsini, 2013).

Along with antioxidant properties, this polyphenol compound exhibit anti-inflammatory, anti-neurodegenerative and anticancer activities (Sarker and Franks, 2018). The potential of curcumin in preventing and treating various agingassociated pathological conditions has been repeatedly reported (Sundar et al., 2018). These conditions include oxidative stress, inflammation, atherosclerosis, cardiovascular and neurodegenerative diseases, type 2 diabetes, osteoporosis, rheumatoid arthritis, age-related kidney and ocular diseases, and also cancer. Over the last decade, the healthspan-promoting potential of this compound has been comprehensively investigated in clinical trials (Salehi et al., 2019). Its bioavailability is, however, limited through its low water solubility and gastrointestinal stability (Kumar et al., 2010). Innovative nanodelivery strategies are currently developed to overcome these limitations (Flora et al., 2013; Ahmad et al., 2014). Both in vitro and in vivo evidence suggests that nanocurcumin formulations have better healthspan-promoting properties than conventional (native) curcumin. The water solubility and bioavailability of this compound were shown to be significantly enhanced by nano-encapsulation with lipid or polymeric nanoparticles, nanogels and dendrimers, and also by conjugating to metal oxide nanoparticles (Shome et al., 2016). In particular, the oral bioavailability of poly lactic-co-glycolic acid (PLGA) curcumin nanoformulation has been shown to be 22 -fold higher than that of native curcumin (Tsai et al., 2011). In a rat model of cerebral ischemia, curcumin-loaded solid lipid nanoparticles demonstrated a 16-fold higher bioavailability of the curcumin in the brain than that of free curcumin (Kakkar et al., 2013). Similarly, oral bioavailability and brain distribution of curcumin were shown to be significantly enhanced in $\mathrm{N}$-trimethyl chitosan surfacemodified solid lipid nanoparticles compared to those of native curcumin (Ramalingam and Ko, 2015).

In in vitro experiments with a Caco- 2 cell line, evidence was also obtained that bovine serum albumin dextran nanoparticles (size up to $200 \mathrm{~nm}$ ) loaded with curcumin may exert significant cellular antioxidant activity (Fan et al., 2018b). The addition of curcumin-loaded nanocapsules produced from the Eudragit L100 polymer to the diets of dairy sheeps resulted in a higher antioxidant capacity and lower lipid peroxidation in their milk (Jaguezeski et al., 2019). Anti-inflammatory activities of different curcumin-loaded nanocomposites were also repeatedly reported (Wang et al., 2015a; Ameruoso et al., 2017; Dewangan et al., 2017; El-Naggar et al., 2019). 


\section{Nano-Quercetin}

Quercetin $\left(3,5,7,3^{\prime}, 4^{\prime}\right.$-pentahydroxyflavone) is a bioactive flavonoid with strong antioxidant properties, including its effects on ROS levels and also on various cellular signal transduction pathways and activities of antioxidant enzymes. In particular, it has displayed the capacity to prevent the oxidation of low-density lipoproteins by scavenging free radicals and chelating transition metal ions. The antioxidant activity of this polyphenolic flavonoid compound is considered to be mainly attributed to its metal ion complexes and complex ions (Xu et al., 2019). When quercetin reacts with a free radical, it donates a proton and becomes a radical itself. The resulting unpaired electron is, however, delocalized by resonance, thereby making the quercetin radical too low in energy to be chemically reactive (Flora, 2009). The antioxidant ability of quercetin is due to the presence of phenolic hydroxyl groups which are accessible to oxidizing agents (Figure 2). There are the B ring o-dihydroxyl groups, the 4-oxo groups in conjugation with the 2,3-alkene, and the 3- and 5-hydroxyl groups (Haq and AlAmro, 2019). All these functional groups may donate electrons to the rings, which increase the number of resonance forms available in addition to those created by the benzene structure. In addition to antioxidant properties, quercetin is known to demonstrate anti-inflammatory, anti-obesity, anti-diabetic, anti-atherosclerotic, anti-hypercholesterolemic, and antihypertensive activities (Anand David et al., 2016). However, its health benefits are limited due to low bioavailability ( $<2 \%$ of the administered dose) (Kawabata et al., 2015; Li et al., 2016). Over the last years, innovative nanotechnology-based approaches have been developed to enhance the quercetin bioavailability. Among them, quercetin-loaded solid lipid nanoparticles have been recently developed that exhibited a significantly improved bioavailability compared to pure quercetin powders (Vijayakumar et al., 2016).

Quercetin-loaded nanoparticles have been also shown to be able to improve antioxidant defense mechanisms in animal models. For example, in a streptozotocin-induced diabetic rat model, quercetin-loaded poly(lactic-co-glycolic acid) nanoparticles with size about $180 \mathrm{~nm}$ demonstrated antioxidant properties similar to those of free quercetin (Chitkara et al., 2012). The same doses of this nanoformulation used in the every-fifth-day dosing regimen have been found to be sufficient to bring effects similar to those from daily doses of the oral quercetin suspension. Similar effects were also observed in pancreas and kidneys for CAT and SOD activities. In rat models, self-emulsifying nanoformulation of quercetin also exhibited a significantly higher antioxidant potential compared to free quercetin when evaluated as a function of capability to combat doxorubicin- and cyclosporin A-induced cardiotoxicity and nephrotoxicity, respectively (Jain et al., 2013). Elevated SOD and CAT activites, GSH levels and amelioration of lipid peroxidation and protein carbonylation were also observed in alloxan-induced diabetic mice treated with quercetin-loaded nanorods (Alam et al., 2016). In addition, quercetin-loaded silica nanoparticles were found to be able to ameliorate inflammatory conditions in different cell lines (Lee et al., 2016).

\section{Nano-Genistein}

Genistein [4',5,7-trihydroxyisoflavone or 5,7-dihydroxy-3-(4hydroxyphenyl) chromen-4-one] is a soy phytoestrogenic isoflavone possessing potent antioxidant activity (Spagnuolo et al., 2015). The antioxidant properties of this isoflavone were shown to be dependent, in particular, on its ability to induce the expression of genes encoding antioxidant enzymes including SOD and CAT (Park et al., 2010). It has been demonstrated to be efficient in combating many age-related disorders, including neurodegenerative diseases, osteoporosis, obesity, type 2 diabetes, and cancer (Saha et al., 2014; Ganai and Farooqi, 2015). However, the clinical use of this compound is often limited due to its low bioavailability. Moreover, it may provoke endocrine-disrupting and toxic effects, especially when applied in high doses (Patisaul, 2017). To overcome these potential side effects, innovative nanotechnological solutions have been recently proposed (Rassu et al., 2018). For example, enhanced oral bioavailability has been revealed in genisteinloaded polymeric nanomicelles in comparison with that for free genistein (Kwon et al., 2007). According to the authors, this effect could be due to higher solubility and gastrointestinal release of nanomicelle-loaded genistein. The oral bioavailability was also found to be improved in genistein loaded in solid lipid nanoparticles compared to that for its suspensions or bulk powders (Kim J. T. et al., 2017). Recently, Pool et al. (2018) found in studies with HT29 human colon cancer cells that incorporation of genistein into small $(\sim 33 \mathrm{~nm})$ PEGylated silica nanoparticles may substantially potentiate its antioxidant effects. These effects were mediated via modulation of endogenous CAT and SOD activities, and $\mathrm{H}_{2} \mathrm{O}_{2}$ production. It leads to induction of apoptosis and autophagy, two processes related to cell death, while only apoptosis was activated by free genistein.

\section{Nano-Epigallocatechin-3-Gallate}

Epigallocatechin-3-gallate [EGCG, (2R, 3R)-5,7-Dihydroxy2-(3,4,5-trihydroxyphenyl) chroman-3-yl 3,4,5trihydroxybenzoate] is one of the major polyphenol (catechin) found in green tea. The molecule of EGCG is very complex (Figure 2), it consists of a gallocatechol group and a gallate ester linked to the flavanol core structure (Botten et al., 2015). The gallocatechol rings in the EGCG structure determine its antioxidant properties since they are able to directly capture free radicals (Braicu et al., 2013). There is convincing evidence that this compound has a stronger antioxidant potential than other green tea catechins, and that it is even more effective in ROS scavenging than vitamins C and E (RiceEvans et al., 1995). EGCG has been also repeatedly shown to exhibit anti-inflammatory, anti-atherogenic and anti-cancer activities (Singh et al., 2011; Shi et al., 2018). The data from epidemiological studies devoted to investigating EGCG are, however, controversial and often conflicting with in vitro findings. This ambiguity could be attributed to its poor stability and bioavailability (Mereles and Hunstein, 2011; Krupkova et al., 2016; Chu et al., 2017). Therefore, in attempt to improve the bioavailability of EGCG, innovative nanodelivery systems have been extensively used (Granja et al., 2017). In particular, 
larger stability and enhanced potential for oral delivery were found in EGCG-loaded solid lipid nanoparticles than those for non-processed EGCG (Frias et al., 2016). Two-fold higher bioavailability of $\mathrm{pH}$-sensitive EGCG-loaded polymeric nanoparticles compared to the native EGCG powder was also demonstrated (Zhang and Zhang, 2018). EGCG-loaded nanoparticles have been also shown to exert antioxidant properties in in vitro models. One example is the study by Avadhani et al. (2017), who synthesized nanotransfersomes containing EGCG and hyaluronic acid (vesicle size $\sim 100 \mathrm{~nm}$ ) aiming to synergize UV radiation-protective capabilities of these compounds. This optimized nanotransfersomal formulation was found to be able to reduce the lipid peroxidation and intracellular ROS levels, and also to increase the viability of human keratinocytes in vitro. EGCG-loaded nanoparticles also have been shown to demonstrate anti-inflammatory activities in in vitro models (Wu et al., 2017).

\section{Nano-Phytoantioxidants in Therapy of Aging Disorders: Preclinical Evidence}

Accumulating evidence indicates that nano-phytoantioxidants have a potential in preventing and treating a wide range of agingassociated pathological conditions. In several animal models, orally administered nano-phytoantioxidants demonstrated a more powerful potential in combating cardio-metabolic disorders than that of their raw forms. Substantial anti-diabetic potential was, e.g., shown in $\mathrm{db} / \mathrm{db}$ diabetic mice administered with nanoparticles loaded with the isoquinoline alkaloid berberine (Xue et al., 2013, 2015). These mice demonstrated a substantial suppression of body weight gain as well as improved glucose tolerance and insulin sensitivity. Substantial hypoglycemic effect was also observed in both normal and diabetic rats administered with selenium-layered nanoparticles loaded with extracts of mulberry leaf and Pueraria lobata (Deng et al., 2019). These nanoparticles were also able to attenuate the oxidative damage, promote glucose utilization by adipocytes and enhance pancreatic function. Solid lipid nanoparticles loaded with the bioactive constituent of kudzu roots, puerarin, showed three times higher bioavailability following oral administration in heart and brain compared to free puerarin (Luo et al., 2011). Treatment with curcuminloaded nanoparticles led to attenuation of palmitate-induced cardiomyocyte apoptosis in $\mathrm{H} 9 \mathrm{C} 2$ embryonic rat heart-derived cells (Li J. et al., 2017). Use of colloidal curcumin nanoparticles dissolved in gum ghatti solution resulted in the restoration of the left ventricular fractional shortening (a violation arising from heart failure following myocardial infarction) in male rats (Sunagawa et al., 2012). In rats administered with solid lipid nanoparticles loaded with extract from Dracocephalum moldavica L., more pronounced therapeutic effects against myocardial ischemia-reperfusion injuries have been revealed in comparison with that of the non-modified extract (Tan et al., 2017). Evidence was also obtained that nano-phytoantioxidant therapy can be a promising solution in treating rheumatoid arthritis, a systemic autoimmune disease caused by chronic inflammatory process occurring in consequence of age-related decline of immune function (immunosenescence) (van Onna and Boonen, 2016). In an adjuvant-induced arthritis rat model, either oral or topical administration of piperineloaded solid lipid nanoparticles caused substantial reduction of the pro-inflammatory cytokine tumor necrosis factor alpha $(\mathrm{TNF} \alpha)$ levels, assuming anti-rheumatic therapeutic potential of such a treatment (Bhalekar et al., 2017). In the same model, the protective potential of curcumin-loaded solid lipid nanoparticles in ameliorating adjuvant-triggered arthritis through attenuating oxido-inflammatory and immunomodulatory cascades was demonstrated (Arora et al., 2015). Nano-phytoantioxidants have been also shown to be efficient for improvement in bone biomechanical parameters and biochemical markers during osteoporosis, a chronic disease characterized by an age-associated deterioration in bone mass and micro-architecture (Barry et al., 2016). Curcumin-loaded poly(lactic-co-glycolicacid) nanoparticles have been found to potentiate protective effects of curcumin against the bone loss in ovariectomized rats (Ahn et al., 2017). In the same model, quercetin-based solid lipid nanoparticles were more effective in restoring bone mineral density in osteopenic animals than free quercetin (Ahmad et al., 2016). In an ovariectomized $\mathrm{C} 57 \mathrm{Bl} / 6$ mice model, the administration of gold curcumin-loaded $\beta$-cyclodextrin conjugated nanoparticles also led to improved bone density and prevented bone loss (Heo et al., 2014).

Innovative nanobiotechnology-based approaches have been also recently developed in anti-cancer therapy. These approaches, in particular, allow drug delivery directly to tumor sites without damaging nearby healthy tissues (Ahmad et al., 2018). In in vitro studies, enhanced anti-tumor activity was obtained, compared to respective unmodified substances, for nanoengineered phytobioactive compounds exerting antioxidant and anti-inflammatory activities such as resveratrol (RodenakKladniew et al., 2017; Wang et al., 2017), curcumin (Meena et al., 2017; Dhivya et al., 2018; Montalban et al., 2018; Wang W. et al., 2018; Ni et al., 2019; Somu and Paul, 2019; van der Vlies et al., 2019), EGCG (Chavva et al., 2019), berberine (Wang et al., 2014a; Zheng et al., 2018), aloe-emodin (Wang et al., 2012; Chen et al., 2014), and oridonin (Wang et al., 2014b). In mouse models of the induced cancer, substantial inhibition of tumor proliferation and angiogenesis and also enhanced levels of apoptosis of cancerous cells have been found in animals administered, either orally or intravenously, with nanoparticles co-loaded with curcumin, along, or in combination with particular anti-cancer drugs (Wang et al., 2015b, 2016; Yang et al., 2015; Yan et al., 2016; Cui et al., 2017; Kumari et al., 2017; Li C. et al., 2017), in comparison to those for free substances. Substantial anti-tumor properties have been also shown for nanoparticles loaded with resveratrol (Xu et al., 2016; Zhang et al., 2019), EGCG (Siddiqui et al., 2014; Tang et al., 2018), quercetin (Gao et al., 2012; Zhu et al., 2017), and berberine (Wang Y. et al., 2018).

The effectiveness of nanotechnology-based systems was also shown in combating neurodegenerative disorders such as Alzheimer's and Parkinson's diseases (Teleanu et al., 2018; Saeedi et al., 2019). Developing such approaches seems to be especially important for this therapeutic area since 
treating these disorders is a very difficult task because of the existence of the blood-brain barrier representing the most important obstacle in delivering pharmaceuticals to the brain. Tunable biophysical properties of nanocomposites allowing to overcome blood-brain barrier make them, potentially, highly useful in these therapeutic applications (Henrich-Noack et al., 2019; Sharma et al., 2019; see also Figure 4 for schematic representation).

In particular, increased oral bioavailability to the brain of nanotechnology-based delivery systems such as curcuminloaded solid lipid nanoparticles (Ramalingam and Ko, 2015, 2016) and resveratrol-loaded N-trimethyl chitosan-g-palmitic acid surface-modified solid lipid nanoparticles (Ramalingam et al., 2016) has been demonstrated compared to the native forms of these phytobioactive compounds. Various nanocomposites administered by intranasal or intravenous routes also provided improved bioavailability to the brain in comparison with that for free drug administration (Gao, 2016). For example, quercetinloaded solid lipid nanoparticles provided enhanced quercetin delivery to the brain along with improved antioxidant effect to brain cells compared to those of pure quercetin, as well as improved memory retention in a rat model of Alzheimer's disease (Dhawan et al., 2011). Increased bioavailability in brain cells was also observed for nanoparticles loaded with piperine (an active ingredient of black pepper) (Yusuf et al., 2012). In an animal model of Alzheimer's disease, the piperine-loaded nanoparticles exhibited therapeutic effects on disease progression, supposedly by reducing oxidative stress and cholinergic degradation. The enhanced bioavailability and improved treatment efficiency of nanoparticles loaded with curcumin, such as curcumin-loaded solid lipid nanoparticles (Kakkar and Kaur, 2011) and poly (lactic-co-glycolic acid) nanoparticles (Cheng et al., 2013) were also shown in mouse models of Alzheimer's disease. Resveratrol and grape extract-loaded solid lipid nanoparticles were also reported to have therapeutic potential for the treatment of this disease (Loureiro et al., 2017). The promising therapeutic potential in preventing and treating Alzheimer's disease has been found for quercetin-loaded nanoparticles as well (Han et al., 2018). The authors assumed that this potential was likely driven by the activity of these nanoparticles to inhibit amyloid $\beta$ aggregation and scavenge free radicals. In a rat model of Alzheimer's disease, evidence was obtained that aluminum chloride-induced adverse neurobehavioral impairments may be attenuated by EGCG-loaded nanoparticles via reducing the formation of neurofibrillary tangles and neuritic plaques (Singh et al., 2018). Moreover, in a mouse model of familial Alzheimer's disease, oral administration with nanoparticles loaded with ascorbic acid and EGCG was shown to enhance

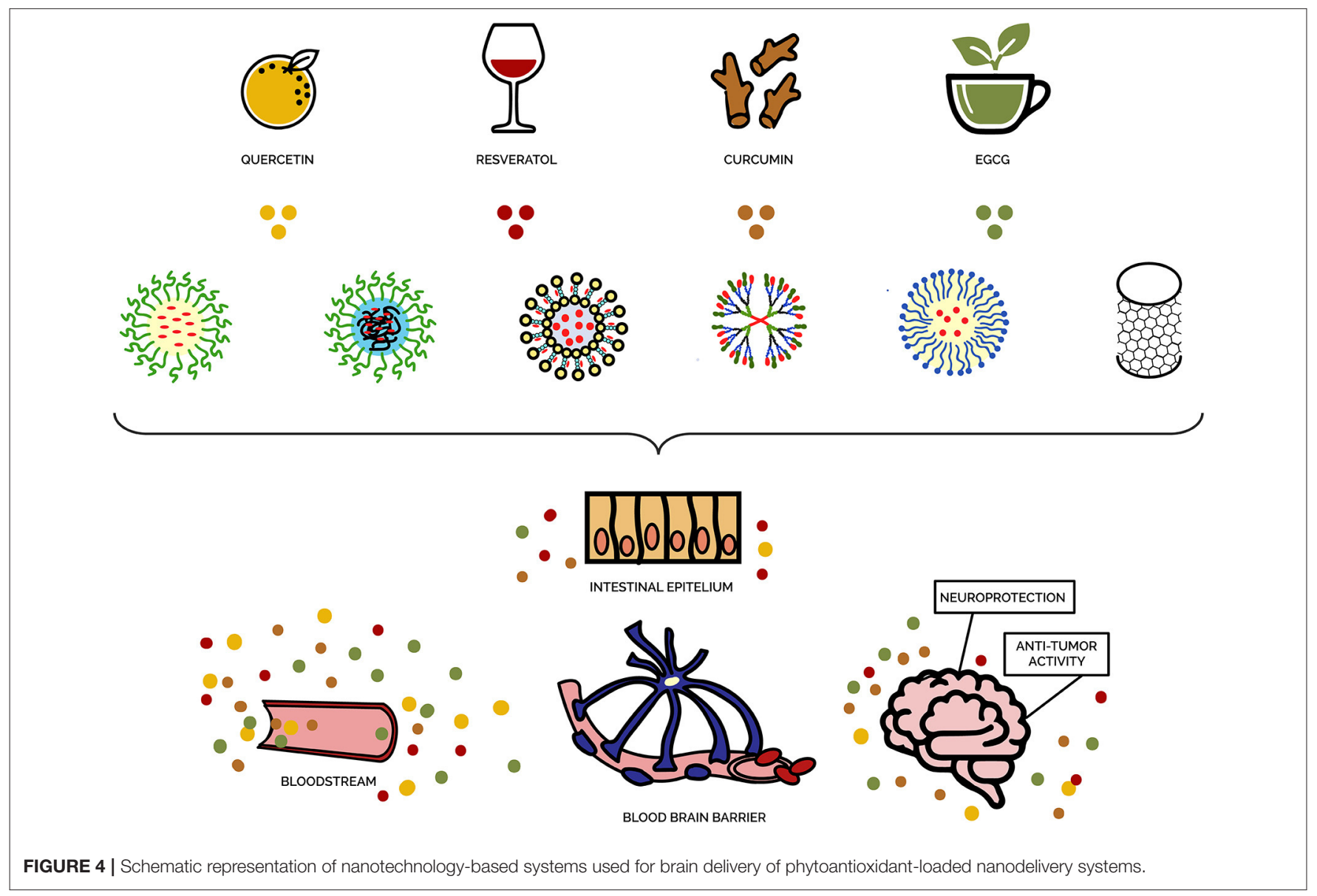


accumulation of EGCG in the brain, as well as to increase the number of synapses and reduce amyloid-beta plaque/peptide accumulation and neuroinflammation (Cano et al., 2019). Nanobiotechnology-based approaches were shown to have a therapeutic potential in treating Parkinson's disease as well. For example, resveratrol-loaded polysorbate 80 -coated poly (lactide) nanoparticles showed protective neuroprotective effects against neurochemical and behavioral impairments caused by neurotoxin (1-methyl-4-phenyl-1,2,3,6-tetrahydropyridine) known to damage dopaminergic neurons and induce Parkinsonlike symptoms in a mouse model of Parkinson's disease (da Rocha Lindner et al., 2015).

\section{CONCLUSIONS}

Oxidative stress caused by imbalance between ROS production and scavenging is undoubtedly one of key contributing factors in most aging-associated pathological conditions. Therefore, the development of therapeutic modalities to combat adverse consequences of oxidative stress, including damage to vital biomolecules, accelerated telomere attrition and systemic inflammation, is one of the most important tasks in current geroscience research. For several decades, dietary supplementation with chemically synthesized antioxidants has been considered as the most appropriate way to prevent and treat ROS-linked disorders. However, more recent studies provided rather controversial and often discouraging results, including increased mortality in those persons who regularly consume synthetic antioxidants such as $\beta$-carotene, vitamin A, and vitamin E (Bjelakovic et al., 2014). Such discouraging results can most likely be explained by the fact that, while assumption on pro-health potential of antioxidants is mostly based on in vitro assays, these assays may not reflect the physiological mechanisms operating in vivo (Shen et al., 2007; Ndhlala et al., 2010). Moreover, the ambiguity of results obtained from epidemiological studies could be likely explained by dichotomous roles of antioxidants in ROS production (Halliwell, 2000; Milisav et al., 2018) and also by important roles of ROS in different vital processes (Schieber and Chandel, 2014; Bardaweel et al., 2018; Milkovic et al., 2019). In addition, as oxidative stress and chronic inflammation coexist in agingassociated pathological conditions, the failing of clinical trials with synthetic antioxidants may be explained by inability to simultaneously target both oxidative stress and inflammatory responses (Biswas, 2016). Indeed, such pharmaceuticals may block several pro-oxidative and/or pro-inflammatory pathways but at the same time strengthen others. On the basis of these considerations, dietary supplementation with natural antioxidants (mostly polyphenols) seems to be a reasonable alternative to synthetic antioxidant intake since natural phytoantioxidants are known to be able to effectively counteract both oxidative stress and inflammation (Petersen and Smith, 2016; Ganesan et al., 2017). The only problem is that in vivo activities of natural antioxidants may be limited owing to their low bioavailability (Shen et al., 2007). Therefore, effects obtained in in vitro experiments could likely be caused by much higher doses than those normally contained in human diet (Scalbert et al., 2005). Therefore, development of nanotechnology-based applications for targeted delivery of bioactive phenolic compounds with antioxidant properties to treat age-related chronic diseases is an urgent task of biotechnological research.

The use of nanocarrier-based systems was shown to enhance the solubility and stability of delivered bioactive phytochemicals, increase their gastrointestinal absorption, and protection from premature enzymatic degradation (Conte et al., 2017; MartínezBallesta et al., 2018). Conclusive evidence suggests that bioavailability of nanoparticle-encapsulated phytochemicals can be 5-10 times higher than that of native formulations (Ganesan et al., 2018a,b). Moreover, such mode of oral delivery may also result in prolonging the circulation time of these compounds, thereby reducing their potential toxicity and side effects. The implementation of nanotherapeutic approaches would likely provide an opportunity to overcome many shortcomings of conventional therapeutic strategies. Using phytochemicalloaded nanoformulations is regarded by many authors as a clinical equivalent to standard treatments with synthetic antioxidants, but with minimizing side effects (Anand et al., 2017). In addition, the beneficial feature of nanodelivery approach is that it can provide an opportunity to deliver phytochemicals to certain organs, such as the brain, following the oral administration.

In conclusion, despite delivery of phyto-antioxidants by nanodelivery systems has apparent healthspan-promoting potential, several important challenges still remain to be addressed. Nanocarriers used to encapsulate phytotherapeuticals have to be comprehensively examined to determine if these nanomaterials themselves could demonstrate adverse health effects, especially if used long-term by patients. Indeed, since the composing chemical(s) may or may not be soluble in biological matrices, the toxicology of applied nanocomposites may differ greatly from that for loaded bioactive substances; it may substantially influence outcomes for different internal organs (De Jong and Borm, 2008). For several nanoantioxidant formulations, a burst drug release may result in concerns related to cellular toxicity, while a slower drug release, on the contrary, may lead to insufficient therapeutic efficacy. Therefore, the development of nanoformulations with release profiles optimized according to the physicochemical properties of carried therapeutic agents presents an essential research challenge that bears further investigation (Lin et al., 2017). Given these considerations, outstanding questions also include: (1) whether applied nanomaterials might bioaccumulate in the human body? (2) Whether they may be converted into potentially dangerous metabolites? (3) Whether they can be completely degraded and subsequently excreted after delivering the therapeutic agent? (4) Whether they can become hazardous after being excreted (in urine or feces of treated patients) and accumulated in living human environments? Given these remaining challenges, it may be concluded that, even though essential steps have been made to bringing nanotherapeutic approaches closer to clinical applications, additional investigation is needed to improve the effectiveness and long-term safety of 
bioactive compound-loaded nanodelivery systems in therapy of aging-associated disorders.

\section{AUTHOR CONTRIBUTIONS}

AV, AK, AZ, and OL conceptualized and designed the manuscript. AV performed literature search and wrote the first draft of the manuscript. AK, AZ, and OL edited the manuscript and constructed the figures. The manuscript was written through

\section{REFERENCES}

Abdal Dayem, A., Hossain, M. K., Lee, S. B., Kim, K., Saha, S. K., Yang, G. M., et al. (2017). The role of reactive oxygen species (ROS) in the biological activities of metallic nanoparticles. Int. J. Mol. Sci. 18:E120. doi: 10.3390/ijms18010120

Ahmad, K., Rabbani, G., Baig, M. H., Lim, J. H., Khan, M. E., Lee, E. J., et al. (2018). Nanoparticle-based drugs: a potential armamentarium of effective anti-cancer therapies. Curr. Drug Metab. 19, 839-846. doi: 10.2174/ 1389200218666170823115647

Ahmad, M. Z., Akhter, S., Mohsin, N., Abdel-Wahab, B. A., Ahmad, J., Warsi, M. H., et al. (2014). Transformation of curcumin from food additive to multifunctional medicine: nanotechnology bridging the gap. Curr. Drug Discov. Technol. 11, 197-213. doi: 10.2174/1570163811666140616153436

Ahmad, N., Banala, V. T., Kushwaha, P., Karvand, A., Sharma, S., Tripathi, A. K., et al. (2016). Quercetin-loaded solid lipid nanoparticles improve osteoprotective activity in an ovariectomized rat model: a preventive strategy for post-menopausal osteoporosis. RSC Adv. 6, 97613-97628. doi: 10.1039/C6RA17141A

Ahn, J., Jeong, J., Lee, H., Sung, M. J., Jung, C. H., Lee, H., et al. (2017). Poly(lacticco-glycolic acid) nanoparticles potentiate the protective effect of curcumin against bone loss in ovariectomized rats. J. Biomed. Nanotech. 13, 688-698. doi: $10.1166 /$ jbn.2017.2372

Ajdary, M., Moosavi, M. A., Rahmati, M., Falahati, M., Mahboubi, M., Mandegary, A., et al. (2018). Health concerns of various nanoparticles: a review of their in vitro and in vivo toxicity. Nanomaterials 8:E634. doi: 10.3390/nano8090634

Alam, M. M., Abdullah, K. M., Singh, B. R., Naqvi, A. H., and Naseem, I. (2016). Ameliorative effect of quercetin nanorods on diabetic mice: mechanistic and therapeutic strategies. RSC Adv. 6, 55092-55103. doi: 10.1039/C6RA04821H

Ameruoso, A., Palomba, R., Palange, A. L., Cervadoro, A., Lee, A., Mascolo, D. D., et al. (2017). Ameliorating amyloid- $\beta$ fibrils triggered inflammation via curcumin-loaded polymeric nanoconstructs. Front. Immunol. 8:1411. doi: 10.3389/fimmu.2017.01411

Anand David, A. V., Arulmoli, R., and Parasuraman, S. (2016). Overviews of biological importance of quercetin: a bioactive flavonoid. Pharmacogn. Rev. 10, 84-89. doi: 10.4103/0973-7847.194044

Anand, K., Tiloke, C., Naidoo, P., and Chuturgoon, A. A. (2017). Phytonanotherapy for management of diabetes using green synthesis nanoparticles. J. Photochem. Photobiol. B 173, 626-639. doi: 10.1016/j.jphotobiol.2017.06.028

Anselmo, A. C., and Mitragotri, S. (2014). An overview of clinical and commercial impact of drug delivery systems. J. Control Release. 190, 15-28. doi: 10.1016/j.jconrel.2014.03.053

Aqil, F., Munagala, R., Jeyabalan, J., and Vadhanam, M. V. (2013). Bioavailability of phytochemicals and its enhancement by drug delivery systems. Cancer Lett. 334, 133-141. doi: 10.1016/j.canlet.2013.02.032

Arora, R., Kuhad, A., Kaur, I. P., and Chopra, K. (2015). Curcumin loaded solid lipid nanoparticles ameliorate adjuvant-induced arthritis in rats. Eur. J. Pain 19, 40-952. doi: 10.1002/ejp.620

Asai, A., and Miyazawa, T. (2000). Occurrence of orally administered curcuminoid as glucuronide and glucuronide/sulfate conjugates in rat plasma. Life Sci. 67, 2785-2793 doi: 10.1016/S0024-3205(00)00868-7

Avadhani, K. S., Manikkath, J., Tiwari, M., Chandrasekhar, M., Godavarthi, A., Vidya, S. M., et al. (2017). Skin delivery of epigallocatechin-3-gallate (EGCG) contributions of all authors. All authors approved the final version of the manuscript.

\section{FUNDING}

The work was partially supported by the Ministry of Education and Science of Ukraine (\#0117U006426) and Science and Technology Center in Ukraine (\#6274) to OL. and hyaluronic acid loaded nano-transfersomes for antioxidant and antiaging effects in UV radiation induced skin damage. Drug Deliv. 24, 61-74. doi: 10.1080/10717544.2016.1228718

Bahadori, E., Farjami, Z., Rezayi, M., Lngari, H., Darroudi, M., Avan, A., et al. (2019). Recent advances in nanotechnology for the treatment of metabolic syndrome. Diabetes Metab. Syndr. 13, 1561-1568. doi: 10.1016/j.dsx.2019.03.002

Bardaweel, S. K., Gul, M., Alzweiri, M., Ishaqat, A., ALSalamat, H. A., and Bashatwah, R. M. (2018). Reactive oxygen species: the dual role in physiological and pathological conditions of the human body. Eurasian J. Med. 50, 193-201. doi: 10.5152/eurasianjmed.2018.17397

Barnes, R. P., Fouquerel, E., and Opresko, P. L. (2019). The impact of oxidative DNA damage and stress on telomere homeostasis. Mech. Ageing Dev. 177, 37-45. doi: 10.1016/j.mad.2018.03.013

Barry, M., Pearce, H., Cross, L., Tatullo, M., and Gaharwar, A. K. (2016). Advances in nanotechnology for the treatment of osteoporosis. Curr. Osteoporos. Rep. 14, 87-94. doi: 10.1007/s11914-016-0306-3

Bayón-Cordero, L., Alkorta, I., and Arana, L. (2019). Application of solid lipid nanoparticles to improve the efficiency of anticancer drugs. Nanomaterials 9:E474. doi: 10.3390/nano9030474

Berman, A. Y., Motechin, R. A., Wiesenfeld, M. Y., and Holz, M. K. (2017). The therapeutic potential of resveratrol: a review of clinical trials. NPJ Precision Oncol. 1:35. doi: 10.1038/s41698-017-0038-6

Bhalekar, M. R., Madgulkar, A. R., Desale, P. S., and Marium, G. (2017). Formulation of piperine solid lipid nanoparticles (SLN) for treatment of rheumatoid arthritis. Drug Dev. Ind. Pharm. 43, 1003-1010. doi: 10.1080/ 03639045.2017.1291666

Bilia, A. R., Piazzini, V., Guccione, C., Risaliti, L., Asprea, M., Capecchi, G., et al. (2017). Improving on nature: the role of nanomedicine in the development of clinical natural drugs. Planta Med. 83, 366-381. doi: 10.1055/s-0043-102949

Biswas, S. K. (2016). Does the interdependence between oxidative stress and inflammation explain the antioxidant paradox? Oxid. Med. Cell. Longev. 2016:5698931. doi: 10.1155/2016/5698931

Bjelakovic, G., Nikolova, D., and Gluud, C. (2014). Antioxidant supplements and mortality. Curr. Opin. Clin. Nutr. Metab. Care. 17, 40-44. doi: 10.1097/MCO.0000000000000009

Borel, T., and Sabliov, C. M. (2014). Nanodelivery of bioactive components for food applications: types of delivery systems, properties, and their effect on ADME profiles and toxicity of nanoparticles. Annu. Rev. Food Sci. Techno. 5, 197-213. doi: 10.1146/annurev-food-030713-092354

Botten, D., Fugallo, G., Fraternali, F., and Molteni, C. (2015). Structural properties of green tea catechins. J. Phys. Chem. B 119, 12860-12867. doi: 10.1021/acs.jpcb.5b08737

Bozzuto, G., and Molinari, A. (2015). Liposomes as nanomedical devices. Int. J. Nanomed. 10, 975-999. doi: 10.2147/IJN.S68861

Braicu, C., Ladomery, M. R., Chedea, V. S., Irimie, A., and BerindanNeagoe, I. (2013). The relationship between the structure and biological actions of green tea catechins. Food Chem. 141, 3282-3289. doi: 10.1016/j.foodchem.2013.05.122

Camins, A., Junyent, F., Verdaguer, E., Beas-Zarate, C., Rojas-Mayorquín, A. E., Ortuño-Sahagún, D., et al. (2009). Resveratrol: an antiaging drug with potential therapeutic applications in treating diseases. Pharmaceuticals 2, 194-205. doi: $10.3390 /$ ph2030194 
Campisi, J., Kapahi, P., Lithgow, G. J., Melov, S., Newman, J. C., and Verdin, E. (2019). From discoveries in ageing research to therapeutics for healthy ageing. Nature 571, 183-192. doi: 10.1038/s41586-019-1365-2

Cano, A., Ettcheto, M., Chang, J. H., Barroso, E., Espina, M., Kühne, B. A., et al. (2019). Dual-drug loaded nanoparticles of Epigallocatechin-3gallate (EGCG)/ Ascorbic acid enhance therapeutic efficacy of EGCG in a APPswe/PS1dE9 Alzheimer's disease mice model. J. Control. Release 301, 62-75. doi: 10.1016/j.jconrel.2019.03.010

Carrizzo, A., Forte, M., Damato, A., Trimarco, V., Salzano, F., and Bartolo, M., et al. (2013). Antioxidant effects of resveratrol in cardiovascular, cerebral and metabolic diseases. Food Chem. Toxicol. 61, 215-226. doi: $10.1016 /$ j.fct.2013.07.021

Cenini, G., Lloret, A., and Cascella, R. (2019). Oxidative stress in neurodegenerative diseases: from a mitochondrial point of view. Oxid. Med. Cell. Longev. 2019:2105607. doi: 10.1155/2019/2105607

Chan, H., and Král, P. (2018). Nanoparticles self-assembly within lipid bilayers. ACS Omega 3, 10631-10637. doi: 10.1021/acsomega.8b01445

Chaudhuri, J., Bains, Y., Guha, S., Kahn, A., Hall, D., Bose, N., et al. (2018). The role of advanced glycation end products in aging and metabolic diseases: bridging association and causality. Cell Metab. 28, 337-352. doi: 10.1016/j.cmet.2018.08.014

Chauhan, A. S. (2015). Dendrimer nanotechnology for enhanced formulation and controlled delivery of resveratrol. Ann. N. Y. Acad. Sci. 1348, 134-140. doi: $10.1111 /$ nyas. 12816

Chavva, S. R., Deshmukh, S. K., Kanchanapally, R., Tyagi, N., Coym, J. W., Singh, A. P., et al. (2019). Epigallocatechin gallate-gold nanoparticles exhibit superior antitumor activity compared to conventional gold nanoparticles: potential synergistic interactions. Nanomaterials 9:E396. doi: 10.3390/nano9030396

Chen, F., Liu, Y., Wong, N. K., Xiao, J., and So, K. F. (2017). Oxidative stress in stem cell aging. Cell Transplant. 26, 1483-1495. doi: 10.1177/0963689717735407

Chen, R., Wang, S., Zhang, J., Chen, M., and Wang, Y. (2014). Aloe-emodin loaded solid lipid nanoparticles: formulation design and in vitro anti-cancer study. Drug Deliv. 22, 666-674. doi: 10.3109/10717544.2014.882446

Chen, Y., Zhang, H., Yang, J., and Sun, H. (2015). Improved antioxidant capacity of optimization of a self-microemulsifying drug delivery system for resveratrol. Molecules 20, 21167-21177. doi: 10.3390/molecules201219750

Cheng, K. K., Yeung, C. F., Ho, S. W., Chow, S. F., Chow, A. H., and Baum, L. (2013). Highly stabilized curcumin nanoparticles tested in an in vitro bloodbrain barrier model and in Alzheimer's disease Tg2576 mice. AAPS J. 15, 324-336. doi: 10.1208/s12248-012-9444-4

Chitkara, D., Nikalaje, S. K., Mittal, A., Chand, M., and Kumar, N. (2012). Development of quercetin nanoformulation and in vivo evaluation using streptozotocin induced diabetic rat model. Drug Deliv. Transl. Res. 2, 112-123. doi: 10.1007/s13346-012-0063-5

Chu, C., Deng, J., Man, Y., and Qu, Y. (2017). Green tea extracts epigallocatechin3-gallate for different treatments. Biomed Res. Int. 2017:5615647. doi: $10.1155 / 2017 / 5615647$

Chun, J. Y., Choi, M. J., Min, S. G., and Weiss, J. (2013). Formation and stability of multiple-layered liposomes by layer-by-layer electrostatic deposition of biopolymers. Food Hydrocoll. 30, 249-257. doi: 10.1016/j.foodhyd.2012.05.024

Conte, R., Marturano, V., Peluso, G., Calarco, A., and Cerruti, P. (2017). Recent advances in nanoparticle-mediated delivery of anti-inflammatory phytocompounds. Int. J. Mol. Sci. 18:E709. doi: 10.3390/ijms18040709

Corrêa, R. C. G., Peralta, R. M., Haminiuk, C. W. I., Maciel, G. M., Bracht, A., and Ferreira, I. C. F. R. (2018). New phytochemicals as potential human antiaging compounds: Reality, promise, and challenges. Crit. Rev. Food Sci. Nutr. 58, 942-957. doi: 10.1080/10408398.2016.1233860

Crimmins, E. M. (2015). Lifespan and healthspan: past, present, and promise. Gerontologist 55, 901-911. doi: 10.1093/geront/gnv130

Crucho, C. I. C., and Barros, M. T. (2017). Polymeric nanoparticles: a study on the preparation variables and characterization methods. Mater. Sci. Eng. C Mater. Biol. Appl. 80, 771-784. doi: 10.1016/j.msec.2017.06.004

Cui, T., Zhang, S., and Sun, H. (2017). Co-delivery of doxorubicin and pHsensitive curcumin prodrug by transferrin-targeted nanoparticles for breast cancer treatment. Oncol. Rep. 37, 1253-1260. doi: 10.3892/or.2017.5345

da Rocha Lindner, G., Bonfanti Santos, D., Colle, D., Gasnhar Moreira, E. L., Daniel Prediger, R., Farina, M., et al. (2015). Improved neuroprotective effects of resveratrol-loaded polysorbate 80 -coated poly(lactide) nanoparticles in MPTPinduced Parkinsonism. Nanomedicine 10, 1127-1138. doi: 10.2217/nnm.14.165

da Silva Santos, V., Badan Ribeiro, A. P., and Andrade Santana, M. H. (2019). Solid lipid nanoparticles as carriers for lipophilic compounds for applications in foods. Food Res. Int. 122, 610-626. doi: 10.1016/j.foodres.2019.01.032

Date, A. A., Hanes, J., and Ensign, L. M. (2016). Nanoparticles for oral delivery: design, evaluation and state-of-the-art. J. Control. Release. 240, 504-526. doi: 10.1016/j.jconrel.2016.06.016

De Jong, W. H., and Borm, P. J. (2008). Drug delivery and nanoparticles: applications and hazards. Int. J. Nanomedicine 3, 133-149. doi: 10.2147/IJN.S596

Deng, W., Wang, H., Wu, B., and Zhang, X. (2019). Selenium-layered nanoparticles serving for oral delivery of phytomedicines with hypoglycemic activity to synergistically potentiate the antidiabetic effect. Acta Pharm. Sin. B 9, 74-86. doi: 10.1016/j.apsb.2018.09.009

Dewangan, A. K., Perumal, Y., Pavurala, N., Chopra, K., and Mazumder, S. (2017). Preparation, characterization and anti-inflammatory effects of curcumin loaded carboxymethyl cellulose acetate butyrate nanoparticles on adjuvant induced arthritis in rats. J. Drug Deliv. Sci. Technol. 41, 269-279. doi: 10.1016/j.jddst.2017.07.022

Dhawan, S., Kapil, R., and Singh, B. (2011). Formulation development and systematic optimization of solid lipid nanoparticles of quercetin for improved brain delivery. J. Pharm. Pharmacol. 63, 342-351. doi: 10.1111/j.2042-7158.2010.01225.x

Dhivya, R., Ranjani, J., Rajendhran, J., Mayandi, J., and Annaraj, J. (2018). Enhancing the anti-gastric cancer activity of curcumin with biocompatible and pH sensitive PMMA-AA/ZnO nanoparticles. Mater. Sci. Eng. C Mater. Biol. Appl. 82, 182-189. doi: 10.1016/j.msec.2017.08.058

Du, L., Li, J., Chen, C., and Liu, Y. (2014). Nanocarrier: a potential tool for future antioxidant therapy. Free Radic. Res. 48, 1061-1069. doi: $10.3109 / 10715762.2014 .924625$

Elliot, P. J., and Jirousek, M. (2008). Sirtuins: novel targets for metabolic disease. Curr. Opin. Investig. Drugs 9, 371-378.

El-Naggar, M. E., Al-Joufi, F., Anwar, M., Attia, M. F., and El-Bana, M. A. (2019). Curcumin-loaded PLA-PEG copolymer nanoparticles for treatment of liver inflammation in streptozotocin-induced diabetic rats. Colloids Surf. B Biointerfaces 177, 389-398. doi: 10.1016/j.colsurfb.2019.02.024

Fan, Y., Liu, Y., Gao, L., Zhang, Y., and Yi, J. (2018a). Improved chemical stability and cellular antioxidant activity of resveratrol in zein nanoparticle with bovine serum albumin-caffeic acid conjugate. Food Chem. 261, 283-291. doi: 10.1016/j.foodchem.2018.04.055

Fan, Y., Yi, J., Zhang, Y., and Yokoyama, W. (2018b). Fabrication of curcumin-loaded bovine serum albumin (BSA)-dextran nanoparticles and the cellular antioxidant activity. Food Chem. 239, 1210-1218. doi: 10.1016/j.foodchem.2017.07.075

Flora, G., Gupta, D., and Tiwari, A. (2013). Nanocurcumin: a promising therapeutic advancement over native curcumin. Crit. Rev. Ther. Drug Carrier Sys. 30, 331-368. doi: 10.1615/CritRevTherDrugCarrierSyst.2013007236

Flora, S. J. (2009). Structural, chemical and biological aspects of antioxidants for strategies against metal and metalloid exposure. Oxid. Med. Cell. Longev. 2, 191-206. doi: 10.4161/oxim.2.4.9112

Forni, C., Facchiano, F., Bartoli, M., Pieretti, S., Facchiano, A., D’Arcangelo, D., et al. (2019). Beneficial role of phytochemicals on oxidative stress and age-related diseases. Biomed Res. Int. 2019:8748253. doi: 10.1155/2019/8748253

Fournet, M., Bont,é, F., and Desmoulière, A. (2018). Glycation damage: a possible hub for major pathophysiological disorders and aging. Aging Dis. 9, 880-900. doi: 10.14336/AD.2017.1121

Frias, I., Neves, A. R., Pinheiro, M., and Reis, S. (2016). Design, development, and characterization of lipid nanocarriers-based epigallocatechin gallate delivery system for preventive and therapeutic supplementation. Drug Des. Devel. Ther. 10, 3519-3528. doi: 10.2147/DDDT.S109589

Fröhlich, E. (2012). The role of surface charge in cellular uptake and cytotoxicity of medical nanoparticles. Int. J. Nanomed. 7, 5577-5591. doi: 10.2147/IJN.S36111

Frozza, R. L., Bernardi, A., Paese, K., Hoppe, J. B., da Silva, T., Battastini, A. M., et al. (2010). Characterization of trans-resveratrol-loaded lipid-core nanocapsules and tissue distribution studies in rats. J. Biomed. Nanotechnol. 6, 694-703. doi: 10.1166/jbn.2010.1161 
Fu, P. P., Xia, Q., Hwang, H. M., Ray, P. C., and Yu, H. (2014). Mechanisms of nanotoxicity: generation of reactive oxygen species. J. Food Drug Anal. 22, 64-75. doi: 10.1016/j.jfda.2014.01.005

Ganai, A. A., and Farooqi, H. (2015). Bioactivity of genistein: a review of in vitro and in vivo studies. Biomed. Pharmacother. 76, 30-38. doi: 10.1016/j.biopha.2015.10.026

Ganesan, P., Arulselvan, P., and Choi, D. K. (2017). Phytobioactive compoundbased nanodelivery systems for the treatment of type 2 diabetes mellitus current status. Int. J. Nanomed. 12, 1097-1111. doi: 10.2147/IJN.S124601

Ganesan, P., Karthivashan, G., Park, S. Y., Kim, J., and Choi, D. K. (2018a). Microfluidization trends in the development of nanodelivery systems and applications in chronic disease treatments. Int. J. Nanomed. 13, 6109-6121. doi: $10.2147 /$ IJN.S178077

Ganesan, P., Ramalingam, P., Karthivashan, G., Ko, Y. T., and Choi, D. K. (2018b). Recent developments in solid lipid nanoparticle and surface-modified solid lipid nanoparticle delivery systems for oral delivery of phyto-bioactive compounds in various chronic diseases. Int. J. Nanomed. 13, 1569-1583. doi: $10.2147 /$ IJN.S155593

Gao, H. (2016). Progress and perspectives on targeting nanoparticles for brain drug delivery. Acta Pharm. Sin. B 6, 268-286. doi: 10.1016/j.apsb.2016.05.013

Gao, X., Wang, B., Wei, X., Men, K., Zheng, F., Zhou, Y., et al. (2012). Anticancer effect and mechanism of polymer micelle-encapsulated quercetin on ovarian cancer. Nanoscale 4, 7021-7030. doi: 10.1039/c2nr32181e

Garaschuk, O., Semchyshyn, H., and Lushchak, V. (2018). Healthy brain aging: interplay between reactive species, inflammation and energy supply. Ageing Res. Rev. 43, 26-45. doi: 10.1016/j.arr.2018.02.003

Gigliobianco, M. R., Casadidio, C., Censi, R., and Di Martino, P. (2018). Nanocrystals of poorly soluble drugs: drug bioavailability and physicochemical stability. Pharmaceutics 10:E134. doi: 10.3390/pharmaceutics10030134

Granja, A., Frias, I., Rute Neves, A., Pinheiro, M., and Reis, S. (2017). Therapeutic potential of epigallocatechin gallate nanodelivery systems. Biomed Res. Int. 2017:5813793. doi: 10.1155/2017/5813793

Grottkau, B. E., Cai, X., Wang, J., Yang, X., and Lin, Y. (2013). Polymeric nanoparticles for a drug delivery system. Curr. Drug Metab. 14, 840-846. doi: 10.2174/138920021131400105

Gruber, J., and Halliwell, B. (2017). Approaches for extending human healthspan: from antioxidants to healthspan pharmacology. Essays Biochem. 61, 389-399. doi: 10.1042/EBC20160091

Gu, M., Wang, X., Toh, T. B., and Chow, E. K. (2018). Applications of stimuliresponsive nanoscale drug delivery systems in translational research. Drug Discov. Today 23, 1043-1052. doi: 10.1016/j.drudis.2017.11.009

Gülçin, I. (2010). Antioxidant properties of resveratrol: a structure-activity insight. Innov. Food Sci. Emerg. Technol. 11, 210-218. doi: 10.1016/j.ifset.2009.07.002

Gupta, R., and Xie, H. (2018). Nanoparticles in daily life: applications, toxicity and regulations. J. Environ. Pathol. Toxicol. Oncol. 37, 209-230. doi: 10.1615/JEnvironPatholToxicolOncol.2018026009

Hajialyani, M., Tewari, D., Sobarzo-Sánchez, E., Nabavi, S. M., Farzaei, M. H., and Abdollahi, M. (2018). Natural product-based nanomedicines for wound healing purposes: therapeutic targets and drug delivery systems. Int. J. Nanomed. 13, 5023-5043. doi: 10.2147/IJN.S174072

Halliwell, B. (2000). The antioxidant paradox. Lancet 355, 1179-1180. doi: 10.1016/S0140-6736(00)02075-4

Han, Q., Wang, H., Cai, S.h., Liu, X., Zhang, Y., Yang, L., et al. (2018). Quercetin nanoparticles with enhanced bioavailability as multifunctional agents toward amyloid induced neurotoxicity. J. Mater. Chem. B 6, 1387-1393. doi: 10.1039/C7TB03053C

Haq, S. H., and AlAmro, A. A. (2019). Neuroprotective effect of quercetin in murine cortical brain tissue cultures. Clin. Nutr. Exp. 23, 89-96. doi: 10.1016/j.yclnex.2018.10.002

Hayashi, M. T. (2018). Telomere biology in aging and cancer: early history and perspectives. Genes Genet. Syst. 92, 107-118. doi: 10.1266/ggs.17-00010

Heinz, H., Pramanik, C., Heinz, O., Ding, Y., Mishra, R. K., Marchon, D., et al. (2017). Nanoparticle decoration with surfactants: molecular interactions, assembly, and applications. Surf. Sci. Rep. 72, 1-58. doi: 10.1016/j.surfrep.2017.02.001

Henrich-Noack, P., Nikitovic, D., Neagu, M., Docea, A. O., Engin, A. B., Gelperina, S., et al. (2019). The blood-brain barrier and beyond: Nano-based neuropharmacology and the role of extracellular matrix. Nanomedicine 17, 359-379. doi: 10.1016/j.nano.2019.01.016

Heo, D. N., Ko, W. K., Moon, H. J., Kim, H. J., Lee, S. J., Lee, J. B., et al. (2014). Inhibition of osteoclast differentiation by gold nanoparticles functionalized with cyclodextrin curcumin complexes. ACS Nano 8, 12049-12062. doi: 10.1021/nn504329u

Hewlings, S. J., and Kalman, D. S. (2017). Curcumin: a review of its' effects on human. Health Foods 6:E92. doi: 10.3390/foods6100092

Hoshyar, N., Gray, S., Han, H., and Bao, G. (2016). The effect of nanoparticle size on in vivo pharmacokinetics and cellular interaction. Nanomedicine 11, 673-692. doi: 10.2217/nnm.16.5

Iavicoli, I., Leso, V., Fontana, L., and Calabrese, E. J. (2018). Nanoparticle exposure and hormetic dose-responses: an update. Int. J. Mol. Sci. 19:E805. doi: 10.3390/ijms19030805

Jaguezeski, A. M., Gündel, S. S., Favarin, F. R., Gündel, A., Souza, C. F., Baldissera, M. D., et al. (2019). Low-dose curcumin-loaded Eudragit L-100-nanocapsules in the diet of dairy sheep increases antioxidant levels and reduces lipid peroxidation in milk. J. Food Biochem. 43:e12942. doi: 10.1111/jfbc. 12942

Jain, S., Jain, A. K., Pohekar, M., and Thanki, K. (2013). Novel self-emulsifying formulation of quercetin for improved in vivo antioxidant potential: implications for drug-induced cardiotoxicity and nephrotoxicity. Free Radic. Biol. Med. 65, 117-130. doi: 10.1016/j.freeradbiomed.2013.05.041

Jaiswal, M., Dudhe, R., and Sharma, P. K. (2015). Nanoemulsion: an advanced mode of drug delivery system. 3 Biotech. 5, 123-127. doi: 10.1007/s13205-014-0214-0

Kakkar, V., and Kaur, I. P. (2011). Evaluating potential of curcumin loaded solid lipid nanoparticles in aluminium induced behavioural, biochemical and histopathological alterations in mice brain. Food Chem. Toxicol. 49, 2906-2913. doi: 10.1016/j.fct.2011.08.006

Kakkar, V., Muppu, S. K., Chopra, K., and Kaur, I. P. (2013). Curcumin loaded solid lipid nanoparticles: an efficient formulation approach for cerebral ischemic reperfusion injury in rats. Eur. J. Pharm. Biopharm. 85, 339-345. doi: 10.1016/j.ejpb.2013.02.005

Kamaly, N., Yameen, B., Wu, J., and Farokhzad, O. C. (2016). Degradable controlled-release polymers and polymeric nanoparticles: mechanisms of controlling drug release. Chem. Rev. 116, 2602-2663. doi: 10.1021/acs.chemrev.5b00346

Kawabata, K., Mukai, R., and Ishisaka, A. (2015). Quercetin and related polyphenols: new insights and implications for their bioactivity and bioavailability. Food Funct. 6, 1399-1417. doi: 10.1039/C4FO01178C

Kermanizadeh, A., Powell, L. G., Stone, V., and Møller, P. (2018). Nanodelivery systems and stabilized solid-drug nanoparticles for orally administered medicine: current landscape. Int. J. Nanomed. 13, 7575-7605. doi: 10.2147/IJN.S177418

Khadka, P., Ro, J., Kim, H., Kim, I., Kim, J. T., Kim, H., et al. (2014). Pharmaceutical particle technologies: an approach to improve drug solubility, dissolution and bioavailability. J. Pharm. Sci. 9, 304-316. doi: 10.1016/j.ajps.2014.05.005

Khan, I., Kumar, H., Mishra, G., Gothwal, A., Kesharwani, P., and Gupta, U. (2017). Polymeric nanocarriers: a new horizon for the effective management of breast cancer. Curr. Pharm. Des. 23, 5315-5326. doi: $10.2174 / 1381612823666170829164828$

Kim, C. S., Park, S., and Kim, J. (2017). The role of glycation in the pathogenesis of aging and its prevention through herbal products and physical exercise. $J$. Exerc. Nutrition. Biochem. 21, 55-61. doi: 10.20463/jenb.2017.0027

Kim, J. T., Barua, S., Kim, H., Hong, S. C., Yoo, S. Y., Jeon, H., et al. (2017). Absorption study of genistein using solid lipid microparticles and nanoparticles: control of oral bioavailability by particle sizes. Biomol. Ther. 25, 452-459. doi: 10.4062/biomolther.2017.095

Koliada, A. K., Krasnenkov, D. S., and Vaiserman, A. M. (2015). Telomeric aging: mitotic clock or stress indicator? Front. Genet. 6:82. doi: 10.3389/fgene.2015.00082

Kong, F. Y., Zhang, J. W., Li, R. F., Wang, Z. X., Wang, W. J., and Wang, W. (2017). Unique roles of gold nanoparticles in drug delivery, targeting and imaging applications. Molecules 22:E1445. doi: 10.3390/molecules22091445

Krishnamoorthy, K., and Mahalingam, M. (2015). Selection of a suitable method for the preparation of polymeric nanoparticles: multi-criteria decision making approach. Adv. Pharm. Bull. 5, 57-67. doi: 10.4103/2231-4040.137410 
Krupkova, O., Ferguson, S. J., and Wuertz-Kozak, K. (2016). Stability of (-)epigallocatechin gallate and its activity in liquid formulations and delivery systems. J. Nutr. Biochem. 37, 1-12. doi: 10.1016/j.jnutbio.2016.01.002

Kumar, A., Ahuja, A., Ali, J., and Baboota, S. (2010). Conundrum and therapeutic potential of curcumin in drug delivery. Crit. Rev. Ther. Drug Carrier Syst. 27, 279-312. doi: 10.1615/CritRevTherDrugCarrierSyst.v27.i4.10

Kumari, P., Muddineti, O. S., Rompicharla, S. V., Ghanta, P., AK, B. B. N., Ghosh, B., et al. (2017). Cholesterol-conjugated poly (D, L-lactide)-based micelles as a nanocarrier system for effective delivery of curcumin in cancer therapy. Drug Deliv. 24, 209-223. doi: 10.1080/10717544.2016.1245365

Kwon, S. H., Kim, S. Y., Ha, K. W., Kang, M. J., Huh, J. S., Im, T. J., et al. (2007). Pharmaceutical evaluation of genistein-loaded pluronic micelles for oral delivery. Arch. Pharm. Res. 30, 1138-1143. doi: 10.1007/BF02980249

Kydd, J., Jadia, R., Velpurisiva, P., Gad, A., Paliwal, S., and Rai, P. (2017). Targeting strategies for the combination treatment of cancer using drug delivery systems. Pharmaceutics 9:E46. doi: 10.3390/pharmaceutics 9040046

Lee, G. H., Lee, S. J., Jeong, S. W., Kim, H. C., Park, G. Y., Lee, S. G., et al. (2016). Antioxidative and antiinflammatory activities of quercetinloaded silica nanoparticles. Colloids. Surf. B Biointerfaces 143, 511-517. doi: 10.1016/j.colsurfb.2016.03.060

Leonov, A., Arlia-Ciommo, A., Piano,. A., Svistkova, V., Lutchman, V., Medkour, Y., et al. (2015). Longevity extension by phytochemicals. Molecules 20, 6544-6572. doi: 10.3390/molecules20046544

Li, C., Ge, X., and Wang, L. (2017). Construction and comparison of different nanocarriers for co-delivery of cisplatin and curcumin: a synergistic combination nanotherapy for cervical cancer. Biomed. Pharmacother. 86, 628-636. doi: 10.1016/j.biopha.2016.12.042

Li, J., Zhou, Y., Zhang, W., Bao, C., and Xie, Z. (2017). Relief of oxidative stress and cardiomyocyte apoptosis by using curcumin nanoparticles. Colloids Surf. B Biointerfaces 153, 174-182. doi: 10.1016/j.colsurfb.2017.02.023

Li, T., Liang, W., Xiao, X., and Qian, Y. (2018). Nanotechnology, an alternative with promising prospects and advantages for the treatment of cardiovascular diseases. Int. J. Nanomed. 13, 7349-7362. doi: 10.2147/IJN.S179678

Li, Y., Yao, J., Han, C., Yang, J., Chaudhry, M. T., Wang, S., et al. (2016). Quercetin, inflammation and immunity. Nutrients 8:167. doi: 10.3390/nu8030167

Lian, B., Wu, M., Feng, Z., Deng, Y., Zhong, C., and Zhao, X. (2019). Folate-conjugated human serum albumin-encapsulated resveratrol nanoparticles: preparation, characterization, bioavailability and targeting of liver tumors. Artif. Cells Nanomed. Biotech. 47, 154-165. doi: $10.1080 / 21691401.2018 .1548468$

Liguori, I., Russo, G., Curcio, F., Bulli, G., Aran, L., Della-Morte, D., et al. (2018). Oxidative stress, aging, and diseases. Clin. Interv. Aging 13, 757-772. doi: $10.2147 /$ CIA.S158513

Lin, C. H., Chen, C. H., Lin, Z. C., and Fang, J. Y. (2017). Recent advances in oral delivery of drugs and bioactive natural products using solid lipid nanoparticles as the carriers. J. Food Drug Anal. 25, 219-234. doi: 10.1016/j.jfda.2017.02.001

Liu, J., Wang, L., Wang, Z., and Liu, J. P. (2019). Roles of telomere biology in cell senescence, replicative and chronological ageing. Cells 8:E54. doi: $10.3390 /$ cells 8010054

Loureiro, J. A., Andrade, S., Duarte, A., Neves, A. R., Queiroz, J. F., Nunes, C., et al. (2017). Resveratrol and grape extract-loaded solid lipid nanoparticles for the treatment of Alzheimer's disease. Molecules 22:E277. doi: 10.3390/molecules22020277

Luo, C. F., Yuan, M., Chen, M. S., Liu, S. M., Zhu, L., Huang, B. Y., et al. (2011). Pharmacokinetics, tissue distribution and relative bioavailability of puerarin solid lipid nanoparticles following oral administration. Int. J. Pharm. 410, 138-144. doi: 10.1016/j.jpharm.2011.02.064

Lushchak, O., Piroddi, M., Galli, F., and Lushchak, V. (2014). Aconitase posttranslational modification as a key in linkage between Krebs cycle, iron homeostasis, redox signaling, and metabolism of reactive oxygen species. Redox Rep. 19, 8-15. doi: 10.1179/1351000213Y.0000000073

Lushchak, O., Zayachkivska, A., and Vaiserman, A. (2018). Metallic nanoantioxidants as potential therapeutics for type 2 diabetes: a hypothetical background and translational perspectives. Oxid. Med. Cell. Longev. 2018:3407375. doi: 10.1155/2018/3407375

Lushchak, V. (2011). Adaptive response to oxidative stress: bacteria, fungi, plants and animals. Comp. Biochem. Physiol. 153.175-190. doi: $10.1016 /$ j.cbpc.2010.10.004
Lushchak, V. (2014). Free radicals, reactive oxygen species, oxidative stress and its classification. Chem. Biol. Interact. 224, 164-175. doi: 10.1016/j.cbi.2014.10.016

Mao, L., and Franke, J. (2013). Hormesis in aging and neurodegenerationa prodigy awaiting dissection. Int. J. Mol. Sci. 14, 13109-13128. doi: 10.3390/ijms140713109

Martel, J., Ojcius, D. M., Ko, Y. F., Chang, C. J., and Young, J. D. (2019). Antiaging effects of bioactive molecules isolated from plants and fungi. Med. Res. Rev. 39, 1515-1552. doi: 10.1002/med.21559

Martínez-Ballesta, M., Gil-Izquierdo, Á., García-Viguera, C., and DomínguezPerles, R. (2018). Nanoparticles and controlled delivery for bioactive compounds: Outlining challenges for new "smart-foods" for health. Foods 7:E72. doi: 10.3390/foods7050072

Meena, R., Kumar, S., Kumar, R., Gaharwar, U. S., and Rajamani, P. (2017). PLGA-CTAB curcumin nanoparticles: fabrication, characterization and molecular basis of anticancer activity in triple negative breast cancer cell lines (MDA-MB-231 cells). Biomed. Pharmacother. 94, 944-954. doi: 10.1016/j.biopha.2017.07.151

Mehnert, W., and Mäder, K. (2001). Solid lipid nanoparticles: production, characterization and applications. Adv. Drug Deliv. Rev. 47, 165-196. doi: 10.1016/S0169-409X(01)00105-3

Mereles, D., and Hunstein, W. (2011). Epigallocatechin-3-gallate (EGCG) for clinical trials: more pitfalls than promises? Int. J. Mol. Sci. 12, 5592-5603. doi: $10.3390 /$ ijms 12095592

Milisav, I., Ribarič, S., and Poljsak, B. (2018). Antioxidant vitamins and ageing. Subcell. Biochem. 90, 1-23. doi: 10.1007/978-981-13-2835-0_1

Milkovic, L., Cipak Gasparovic, A., Cindric, M., Mouthuy, P. A., and Zarkovic, N. (2019). Short overview of ROS as cell function regulators and their implications in therapy concepts. Cells 8:E793. doi: 10.3390/cells8080793

Mishra, V., Bansal, K. K., Verma, A., Yadav, N., Thakur, S., Sudhakar, K., et al. (2018). Solid lipid nanoparticles: emerging colloidal nano drug delivery systems. Pharmaceutics 10:E191. doi: 10.3390/pharmaceutics100 40191

Mody, V. V., Siwale, R., Singh, A., and Mody, H. R. (2010). Introduction to metallic nanoparticles. J. Pharm. Bioallied Sci. 2, 282-289. doi: 10.4103/0975-7406. 72127

Montalban, M. G., Coburn, J. M., Lozano-Perez, A. A., Cenis, J. L., Villora, G., and Kaplan, D. L. (2018). Production of curcumin-loaded silk fibroin nanoparticles for cancer therapy. Nanomaterials 8:E126. doi: 10.3390/nano8020126

Moss, D. M., Curley, P., Kinvig, H., Hoskins, C., and Owen, A. (2018). The biological challenges and pharmacological opportunities of orally administered nanomedicine delivery. Exp. Rev. Gastroenterol. Hepatol. 12, 223-236. doi: 10.1080/17474124.2018.1399794

Myers, A., and Lithgow, G. J. (2019). Drugs that target aging: how do we discover them? Exp Opin. Drug Discov. 14, 541-548. doi: $10.1080 / 17460441.2019 .1597049$

Myung, S. K., Ju, W., Cho, B., Oh, S. W., Park, S. M., Koo, B. K., et al. (2013). Korean meta-analysis study group. Efficacy of vitamin and antioxidant supplements in prevention of cardiovascular disease: systematic review and meta-analysis of randomised controlled trials. BMJ 346:f10. doi: 10.1136/bmj.f10

Naseri, N., Valizadeh, H., and Zakeri-Milani, P. (2015). Solid lipid nanoparticles and nanostructured lipid carriers: structure, preparation and application. $A d v$. Pharm. Bull. 5, 305-313. doi: 10.15171/apb.2015.043

Ndhlala, A. R., Moyo, M., and Van Staden, J. (2010). Natural antioxidants: fascinating or mythical biomolecules? Molecules 15, 6905-6930. doi: 10.3390/molecules 15106905

Neha, K., Haider, M. R., Pathak, A., and Yar, M. S. (2019). Medicinal prospects of antioxidants: a review. Eur. J. Med. Chem. 178, 687-704. doi: 10.1016/j.ejmech.2019.06.010

Nel, A., Xia, T., Mädler, L., and Li, N. (2006). Toxic potential of materials at the nanolevel. Science 311, 622-627. doi: 10.1126/science.1114397

Ni, W., Li, Z., Liu, Z., Ji, Y., Wu, L., Sun, S., et al. (2019). Dualtargeting nanoparticles: codelivery of curcumin and 5-fluorouracil for synergistic treatment of hepatocarcinoma. J. Pharm. Sci. 108, 1284-1295. doi: 10.1016/j.xphs.2018.10.042

Pajares, M., Cuadrado, A., Engedal, N., Jirsova, Z., and Cahova, M. (2018). The role of free radicals in autophagy regulation: implications for ageing. Oxid. Med. Cell. Longev. 2018:2450748. doi: 10.1155/2018/2450748 
Pan, L., Qiu, H., Dou, C., Li, Y., Pu, L., Xu, J., et al. (2010). Conducting polymer nanostructures: template synthesis and applications in energy storage. Int. J. Mol. Sci. 11, 2636-2657. doi: 10.3390/ijms11072636

Pangeni, R., Sharma, S., Mustafa, G., Ali, J., and Baboota, S. (2014). Vitamin E loaded resveratrol nanoemulsion for brain targeting for the treatment of Parkinson's disease by reducing oxidative stress. Nanotechnology 25:485102. doi: 10.1088/0957-4484/25/48/485102

Pannu, N., and Bhatnagar, A. (2019). Resveratrol: from enhanced biosynthesis and bioavailability to multitargeting chronic diseases. Biomed. Pharmacother. 109, 2237-2251. doi: 10.1016/j.biopha.2018.11.075

Park, C. E., Yun, H., Lee, E. B., Min, B. I., Bae, H., Choe, W., et al. (2010). The antioxidant effects of genistein are associated with AMP-activated protein kinase activation and PTEN induction in prostate cancer cells. J. Med. Food. 13, 815-820. doi: 10.1089/jmf.2009.1359

Patisaul, H. B. (2017). Endocrine disruption by dietary phyto-oestrogens: impact on dimorphic sexual systems and behaviours. Proc. Nutr. Soc. 76, 130-144. doi: 10.1017/S0029665116000677

Patra, J. K., Das, G., Fraceto, L. F., Campos, E. V. R., Rodriguez-Torres, M. D. P., Acosta-Torres, L. S., et al. (2018). Nano based drug delivery systems: recent developments and future prospects. J. Nanobiotechnol. 16:71. doi: 10.1186/s12951-018-0392-8

Pervin, M., Unno, K., Takagaki, A., Isemura, M., and Nakamura, Y. (2019). Function of green tea catechins in the brain: epigallocatechin gallate and its metabolites. Int. J. Mol. Sci. 20:E3630. doi: 10.3390/ijms20153630

Petersen, K. S., and Smith, C. (2016). Ageing-associated oxidative stress and inflammation are alleviated by products from grapes. Oxid. Med. Cell. Longev. 2016:6236309. doi: 10.1155/2016/6236309

Piazzini, V., Lemmi, B., D’Ambrosio, M., Cinci, L., Luceri, C., Bilia, A. R., et al. (2018). Nanostructured lipid carriers as promising delivery systems for plant extracts: the case of silymarin. Appl. Sci. 8:1163. doi: 10.3390/app8071163

Pippa, N., Pispas, S., and Demetzos, C. (2016). Polymer self-assembled nanostructures as innovative drug nanocarrier platforms. Curr. Pharm. Des. 22, 2788-2795. doi: 10.2174/1381612822666160217141232

Pizzino, G., Irrera, N., Cucinotta, M., Pallio, G., Mannino, F., Arcoraci, V., et al. (2017). Oxidative stress: harms and benefits for human health. Oxid. Med. Cell. Longev. 2017:8416763. doi: 10.1155/2017/8416763

Pool, H., Campos-Vega, R., Herrera-Hernández, M. G., García-Solis, P., GarcíaGasca, T., Sánchez, I. C., et al. (2018). Development of genistein-PEGylated silica hybrid nanomaterials with enhanced antioxidant and antiproliferative properties on HT29 human colon cancer cells. Am. J. Transl. Res. 10, 2306-2323.

Poovaiah, N., Davoudi, Z., Peng, H., Schlichtmann, B., Mallapragada, S., Narasimhan, B., et al. (2018). Treatment of neurodegenerative disorders through the blood-brain barrier using nanocarriers. Nanoscale 10, 16962-16983. doi: 10.1039/C8NR04073G

Popat, R., Plesner, T., Davies, F., Cook, G., Cook, M., Elliott, P., et al. (2013). A phase 2 study of SRT501 (resveratrol) with bortezomib for patients with relapsed and or refractory multiple myeloma. Br. J. Haematol. 160, 714-717. doi: $10.1111 /$ bjh.12154

Priyadarsini, K. I. (2013). Chemical and structural features influencing the biological activity of curcumin. Curr. Pharm. Des. 19, 2093-2100. doi: $10.2174 / 1381612811319110010$

Priyadarsini, K. I. (2014). The chemistry of curcumin: from extraction to therapeutic agent. Molecules 19, 20091-22112. doi: 10.3390/molecules 191220091

Qiao, Y., Wan, J., Zhou, L., Ma, W., Yang, Y., Luo, W., et al. (2019). Stimuli-responsive nanotherapeutics for precision drug delivery and cancer therapy. Wiley Interdiscip. Rev. Nanomed. Nanobiotechnol. 11:e1527. doi: 10.1002/wnan.1527

Rahal, A., Kumar, A., Singh, V., Yadav, B., Tiwari, R., Chakraborty, S., et al. (2014). Oxidative stress, prooxidants, and antioxidants: the interplay. Biomed Res. Int. 2014:761264. doi: 10.1155/2014/761264

Ramalingam, P., and Ko, Y. T. (2015). Enhanced oral delivery of curcumin from N-trimethyl chitosan surface-modified solid lipid nanoparticles: pharmacokinetic and brain distribution evaluations. Pharm. Res. 32, 89-402. doi: 10.1007/s11095-014-1469-1

Ramalingam, P., and Ko, Y. T. (2016). Improved oral delivery of resveratrol from $\mathrm{N}$-trimethyl chitosan-g-palmitic acid surface-modified solid lipid nanoparticles. Colloids Surf. B Biointerfaces 139, 52-61. doi: 10.1016/j.colsurfb.2015.11.050

Ramalingam, P., Yoo, S. W., and Ko, Y. T. (2016). Nanodelivery systems based on mucoadhesive polymer coated solid lipid nanoparticles to improve the oral intake of food curcumin. Food Res. Int. 84, 113-119. doi: 10.1016/j.foodres.2016.03.031

Ramanathan, S., Archunan, G., Sivakumar, M., Tamil Selvan, S., Fred, A. L., Kumar, S., et al. (2018). Theranostic applications of nanoparticles in neurodegenerative disorders. Int. J. Nanomed. 13, 5561-5576. doi: 10.2147/IJN.S149022

Ramírez-Garza, S. L., Laveriano-Santos, E. P., Marhuenda-Muñoz, M., Storniolo, C. E., Tresserra-Rimbau, A., Vallverdú-Queralt, A., et al. (2018). Health effects of resveratrol: results from human intervention trials. Nutrients 10:E1892. doi: 10.3390/nu10121892

Rassu, G., Porcu, E. P., Fancello, S., Obinu, A., Senes, N., Galleri, G., et al. (2018). Intranasal delivery of genistein-loaded nanoparticles as a potential preventive system against neurodegenerative disorders. Pharmaceutics 11:E8. doi: 10.3390/pharmaceutics11010008

Rastogi, R., Anand, S., and Koul, V. (2009). Flexible polymerosomes-an alternative vehicle for topical delivery. Colloids Surf. B Biointerfaces 72, 161-166. doi: 10.1016/j.colsurfb.2009.03.022

Ravindran, S., Suthar, J. K., Rokade, R., Deshpande, P., Singh, P., Pratinidhi, A., et al. (2018). Pharmacokinetics, metabolism, distribution and permeability of nanomedicine. Curr. Drug Metab. 19, 327-334. doi: 10.2174/1389200219666180305154119

Rice-Evans, C. A., Miller, N. J., Bolwell, P. G., Bramley, P. M., and Pridham, J. B. (1995). The relative antioxidant activities of plant-derived polyphenolic flavonoids. Free Radic. Res. 22, 375-383. doi: 10.3109/10715769509145649

Rizvi, S. A. A., and Saleh, A. M. (2018). Applications of nanoparticle systems in drug delivery technology. Saudi Pharm. J. 26, 64-70. doi: $10.1016 /$ j.jsps.2017.10.012

Rodenak-Kladniew, B., Islan, G. A., de Bravo, M. G., Durán, N., and Castro, G. R. (2017). Design, characterization and in vitro evaluation of linalool-loaded solid lipid nanoparticles as potent tool in cancer therapy. Colloids Surf. B Biointerfaces 154, 123-132. doi: 10.1016/j.colsurfb.2017.03.021

Sadowska-Bartosz, I., and Bartosz, G. (2014). Effect of antioxidants supplementation on aging and longevity. Biomed Res. Int. 2014:404680. doi: 10.1155/2014/404680

Saeedi, M., Eslamifar, M., Khezri, K., and Dizaj, S. M. (2019). Applications of nanotechnology in drug delivery to the central nervous system. Biomed. Pharmacother. 111, 666-675. doi: 10.1016/j.biopha.2018.12.133

Saha, S., Sadhukhan, P., and Sil, P. C. (2014). Genistein: a phytoestrogen with multifaceted therapeutic properties. Mini Rev. Med. Chem. 14, 920-940. doi: 10.2174/1389557514666141029233442

Salehi, B., Mishra, A. P., Nigam, M., Sener, B., Kilic, M., Sharifi-Rad, M., et al. (2018). Resveratrol: a double-edged sword in health benefits. Biomedicines 6:E91. doi: 10.3390/biomedicines6030091

Salehi, B., Stojanović-Radić, Z., Matejić, J., Sharifi-Rad, M., Anil Kumar, N. V., Martins, N., et al. (2019). The therapeutic potential of curcumin: a review of clinical trials. Eur. J. Med. Chem. 163, 527-545. doi: 10.1016/j.ejmech.2018.12.016

Sandhir, R., Yadav, A., Sunkaria, A., and Singhal, N. (2015). Nano-antioxidants: an emerging strategy for intervention against neurodegenerative conditions. Neurochem. Int. 89, 209-226. doi: 10.1016/j.neuint.2015.08.011

Santos, A. L., Sinha, S., and Lindner, A. B. (2018). The good, the bad, and the ugly of ROS: new insights on aging and aging-related diseases from eukaryotic and prokaryotic model organisms. Oxid. Med. Cell. Longev. 2018:1941285. doi: 10.1155/2018/1941285

Sarker, M. R., and Franks, S. F. (2018). Efficacy of curcumin for age-associated cognitive decline: a narrative review of preclinical and clinical studies. Geroscience 40, 73-95. doi: 10.1007/s11357-018-0017-z

Scalbert, A., Johnson, I. T., and Saltmarsh, M. (2005). Polyphenols: antioxidants and beyond. Am. J. Clin. Nutr. 81, 215S-217S. doi: 10.1093/ajcn/81. $1.215 \mathrm{~S}$

Schieber, M., and Chandel, N. S. (2014). ROS function in redox signaling and oxidative stress. Curr. Biol. 24, R453-R462. doi: 10.1016/j.cub.2014.03.034

Seals, D. R., Justice, J. N., and LaRocca, T. J. (2016). Physiological geroscience: targeting function to increase healthspan and achieve optimal longevity. $J$. Physiol. 594, 2001-2024. doi: 10.1113/jphysiol.2014.282665 
Seals, D. R., and Melov, S. (2014). Translational geroscience: emphasizing function to achieve optimal longevity. Aging 6, 718-370. doi: 10.18632/aging.100694

Sedlak, L., Wojnar, W., Zych, M., Wygledowska-Promienska, D., MrukwaKominek, E., and Kaczmarczyk-Sedlak, I. (2018). Effect of resveratrol, a dietary-derived polyphenol, on the oxidative stress and polyol pathway in the lens of rats with streptozotocin-induced diabetes. Nutrients 10:E1423. doi: $10.3390 /$ nu10101423

Serino, A., and Salazar, G. (2018). Protective role of polyphenols against vascular inflammation, aging and cardiovascular disease. Nutrients 11:E53. doi: 10.3390/nu11010053

Sharma, G., Sharma, A. R., Lee, S. S., Bhattacharya, M., Nam, J. S., and Chakraborty, C. (2019). Advances in nanocarriers enabled brain targeted drug delivery across blood brain barrier. Int. J. Pharm. 559, 360-372. doi: 10.1016/j.ijpharm.2019.01.056

Shen, L., Hong-Fang, J., and Hong-Yu, Z. (2007). How to understand the dichotomy of antioxidants. Biochem. Biophys. Res. Commun. 362, 543-545. doi: 10.1016/j.bbrc.2007.07.125

Shi, M., Shi, Y. L., Li, X. M., Yang, R., Cai, Z. Y., Li, Q. S., et al. (2018). Foodgrade encapsulation systems for (-)-epigallocatechin gallate. Molecules 23:E445. doi: 10.3390/molecules 23020445

Shome, S., Talukdar, A. D., Choudhury, M. D., Bhattacharya, M. K., and Upadhyaya, H. (2016). Curcumin as potential therapeutic natural product: a nanobiotechnological perspective. J. Pharm. Pharmacol. 68, 1481-1500. doi: $10.1111 /$ jphp. 12611

Siddiqui, I. A., Bharali, D. J., Nihal, M., Adhami,. V. M., Khan, N., Chamcheu, J. C., et al. (2014). Excellent anti-proliferative and pro-apoptotic effects of (-)-epigallocatechin-3-gallate encapsulated in chitosan nanoparticles on human melanoma cell growth both in vitro and in vivo. Nanomedicine 10, 1619-1626. doi: 10.1016/j.nano.2014.05.007

Singh, A. P., Singh, R., Verma, S. S., Rai, V., Kaschula, C. H., Maiti, P., et al. (2019). Health benefits of resveratrol: evidence from clinical studies. Med. Res. Rev. 39, 1851-1891. doi: 10.1002/med.21565

Singh, B. N., Shankar, S., and Srivastava, R. K. (2011). Green tea catechin, epigallocatechin-3-gallate (EGCG): mechanisms, perspectives and clinical applications. Biochem. Pharmacol. 82, 1807-1821. doi: 10.1016/j.bcp.2011.07.093

Singh, N. A., Bhardwaj, V., Ravi, C., Ramesh, N., Mandal, A. K. A., and Khan, Z. A. (2018). EGCG nanoparticles attenuate aluminum chloride induced neurobehavioral deficits, beta amyloid and tau pathology in a rat model of Alzheimer's disease. Front. Aging Neurosci. 10:244. doi: 10.3389/fnagi.2018.00244

Singh, R., and Lillard, J. W. Jr. (2009). Nanoparticle-based targeted drug delivery. Exp. Mol. Pathol. 86, 215-223. doi: 10.1016/j.yexmp.2008.12.004

Siu, F. Y., Ye, S., Lin, H., and Li, S. (2018). Galactosylated PLGA nanoparticles for the oral delivery of resveratrol: enhanced bioavailability and in vitro anti-inflammatory activity. Int. J. Nanomed. 13, 4133-4144. doi: $10.2147 /$ IJN.S164235

Smith, R. E., Tran, K., Smith, C. C., McDonald, M., Shejwalkar, P., and Hara, K. (2016). The role of the Nrf2/ARE antioxidant system in preventing cardiovascular diseases. Diseases 4:E34. doi: 10.3390/diseases40 40034

Smoliga, J. M., and Blanchard, O. (2014). Enhancing the delivery of resveratrol in humans: if low bioavailability is the problem, what is the solution? Molecules 19, 17154-17172. doi: 10.3390/molecules191117154

Smoliga, J. M., Vang, O., and Baur, J. A. (2012). Challenges of translating basic research into therapeutics: resveratrol as an example. J. Gerontol. A Biol. Sci. Med. Sci. 67, 158-167. doi: 10.1093/gerona/glr062

Somu, P., and Paul, S. (2019). Supramolecular nanoassembly of lysozyme and $\alpha$-lactalbumin (apo $\alpha$-LA) exhibits selective cytotoxicity and enhanced bioavailability of curcumin to cancer cells. Colloids Surf. B Biointerfaces 178, 297-306. doi: 10.1016/j.colsurfb.2019.03.016

Spagnuolo, C., Russo, G. L., Orhan, I. E., Habtemariam, S., Daglia, M., Sureda, A., et al. (2015). Genistein and cancer: current status, challenges, and future directions. Adv. Nutr. 6, 408-419. doi: 10.3945/an.114.008052

Sunagawa, Y., Wada, H., Suzuki, H., Sasaki, H., Imaizumi, A., Fukuda, H., et al. (2012). A novel drug delivery system of oral curcumin markedly improves efficacy of treatment for heart failure after myocardial infarction in rats. Biol. Pharm. Bull. 35, 139-144. doi: 10.1248/bpb.35.139
Sundar, D. K. S., Houreld, N. N., and Abrahamse, H. (2018). Therapeutic potential and recent advances of curcumin in the treatment of aging-associated diseases. Molecules 23:E835. doi: 10.3390/molecules23040835

Tan, B. L., Norhaizan, M. E., Liew, W. P., and Sulaiman Rahman, H. (2018). Antioxidant and oxidative stress: a mutual interplay in age-related diseases. Front. Pharmacol. 9:1162. doi: 10.3389/fphar.2018.01162

Tan, M. E., He, C. H., Jiang, W., Zeng, C., Yu, N., Huang, W., et al (2017). Development of solid lipid nanoparticles containing total flavonoid extract from Dracocephalum moldavica L. and their therapeutic effect against myocardial ischemia-reperfusion injury in rats. Int. J. Nanomed. 12, 253-3265. doi: $10.2147 /$ IJN.S131893

Taneja, G., Sud, A., Pendse, N., Panigrahi, B., Kumar, A., and Sharma, A. K. (2019). Nano-medicine and vascular endothelial dysfunction: options and delivery strategies. Cardiovasc. Toxicol. 19, 1-12. doi: 10.1007/s12012-018-9491-x

Tang, P., Sun, Q., Yang, H., Tang, B., Pu, H., and Li, H. (2018). Honokiol nanoparticles based on epigallocatechin gallate functionalized chitin to enhance therapeutic effects against liver cancer. Int. J. Pharm. 545, 74-83. doi: 10.1016/j.ijpharm.2018.04.060

Teleanu, D. M., Chircov, C., Grumezescu, A. M., Volceanov, A., and Teleanu, R. I. (2018). Blood-brain delivery methods using nanotechnology. Pharmaceutics 10:269. doi: 10.3390/pharmaceutics10040269

Toledo-Ibelles, P., and Mas-Oliva, J. (2018). Antioxidants in the fight against atherosclerosis: is this a dead end? Curr. Atheroscler. Rep. 20:36. doi: 10.1007/s11883-018-0737-7

Tsai, Y. M., Jan, W. C., Chien, C. F., Lee, W. C., Lin, L. C., and Tsai, T. H. (2011). Optimised nano-formulation on the bioavailability of hydrophobic polyphenol, curcumin, in freely-moving rats. Food Chem. 127, 918-925. doi: $10.1016 /$ j.foodchem.2011.01.059

Tsou, Y. H., Wang, B., Ho, W., Hu, B., Tang, P., Sweet, S., et al. (2019). Nanotechnology-mediated drug delivery for the treatment of obesity and its related comorbidities. Adv. Healthc. Mater. 8:e1801184. doi: 10.1002/adhm.201801184

Tuguntaev, R. G., Okeke, C. I., Xu, J., Li, C., Wang, P. C., and Liang, X. J. (2016). Nanoscale polymersomes as anti-cancer drug carriers applied for pharmaceutical delivery. Curr. Pharm. Des. 22, 2857-2865. doi: $10.2174 / 1381612822666160217142319$

Vaiserman, A., and Lushchak, O. (2017). Implementation of longevitypromoting supplements and medications in public health practice: achievements, challenges and future perspectives. J. Transl. Med. 15:160. doi: 10.1186/s12967-017-1259-8

Vaiserman, A. M., and Marotta, F. (2016). Longevity-promoting pharmaceuticals: is it a time for implementation? Trends Pharmacol. Sci. 37, 331-333. doi: $10.1016 /$ j.tips.2016.02.003

van der Vlies, A. J., Morisaki, M., Neng, H. I., Hansen, E. M., and Hasegawa, U. (2019). Framboidal nanoparticles containing a curcumin-phenylboronic acid complex with antiangiogenic and anticancer activities. Bioconjug. Chem. 30, 861-870. doi: 10.1021/acs.bioconjchem.9b00006

van Onna, M., and Boonen, A. (2016). The challenging interplay between rheumatoid arthritis, ageing and comorbidities. BMC Musculoskelet. Disord. 17:184. doi: 10.1186/s12891-016-1038-3

Vanaja, K., Wahl, M. A., Bukarica, L., and Heinle, H. (2013). Liposomes as carriers of the lipid soluble antioxidant resveratrol: evaluation of amelioration of oxidative stress by additional antioxidant vitamin. Life Sci. 93, 917-923. doi: $10.1016 /$ j.lfs.2013.10.019

Verdile, G., Keane, K. N., Cruzat, V. F., Medic, S., Sabale, M., Rowles, J., et al. (2015). Inflammation and oxidative stress: the molecular connectivity between insulin resistance, obesity, and alzheimer's disease. Mediators Inflamm. 2015:105828. doi: 10.1155/2015/1 05828

Vijayakumar, A., Baskaran, R., Jang, Y. S., Oh, S. H., and Yoo, B. K. (2016). Quercetin-loaded solid lipid nanoparticle dispersion with improved physicochemical properties and cellular uptake. AAPS Pharm. Sci. Tech. 18, 875-883. doi: 10.1208/s12249-016-0573-4

Wahl, D., Bernier, M., Simpson, S. J., de Cabo, R., and Le Couteur, D. G. (2018). Future directions of resveratrol research. Nutr. Healthy Aging 4, 287-290. doi: 10.3233/NHA-170035

Walle, T. (2011). Bioavailability of resveratrol. Ann. N. Y. Acad. Sci. 1215, 9-15. doi: $10.1111 / j .1749-6632.2010 .05842 . x$ 
Wang, J., Ma, W., and Tu, P. (2015b). Synergistically improved anti-tumor efficacy by co-delivery doxorubicin and curcumin polymeric micelles. Macromol. Biosci. 15, 1252-1261. doi: 10.1002/mabi.201500043

Wang, J., Wang, H., Zhu, R., Liu, Q., Fei, J., and Wang, S. (2015a). Antiinflammatory activity of curcumin-loaded solid lipid nanoparticles in IL$1 \mathrm{~b}$ transgenic mice subjected to the lipopolysaccharide-induced sepsis. Biomaterials 53, 475-483. doi: 10.1016/j.biomaterials.2015.02.116

Wang, L., Li, H., Wang, S., Liu, R., Wu, Z., Wang, C., et al. (2014a). Enhancing the antitumor activity of berberine hydrochloride by solid lipid nanoparticle encapsulation. AAPS Pharm. Sci. Tech. 15, 834-844. doi: 10.1208/s12249-014-0112-0

Wang, L., Wang, S., Chen, R., Wang, Y., Li, H., Wang, Y., et al. (2014b). Oridonin loaded solid lipid nanoparticles enhanced antitumor activity in MCF-7 cells. J. Nanomater. 2014:903646. doi: 10.1155/2014/903646

Wang, L., Wang, W., Rui, Z., and Zhou, D. (2016). The effective combination therapy against human osteosarcoma: doxorubicin plus curcumin coencapsulated lipid-coated polymeric nanoparticulate drug delivery system. Drug Deliv. 23, 3200-3208. doi: 10.3109/10717544.2016.1162875

Wang, S., Chen, T., Chen, R., Hu, Y., Chen, M., and Wang, Y. (2012). Emodin loaded solid lipid nanoparticles: preparation, characterization and antitumor activity studies. Int. J. Pharm. 430, 238-246. doi: 10.1016/j.ijpharm.2012.03.027

Wang, W., Chen, T., Xu, H., Ren, B., Cheng, X., Qi, R., et al. (2018). Curcuminloaded solid lipid nanoparticles enhanced anticancer efficiency in breast cancer. Molecules 23:E1578. doi: 10.3390/molecules23071578

Wang, W., Zhang, L., Chen, T., Guo, W., Bao, X., Wang, D., et al. (2017). Anticancer effects of resveratrol-loaded solid lipid nanoparticles on human breast cancer cells. Molecules 22:E1814. doi: 10.3390/molecules22111814

Wang, Y., Wen, B., Yu, H., Ding, D., Zhang, J., Zhang, Y., et al. (2018). Berberine hydrochloride-loaded chitosan nanoparticles effectively targets and suppresses human nasopharyngeal carcinoma. J. Biomed. Nanotechnol. 14, 1486-1495. doi: $10.1166 /$ jbn.2018.2596

Watal, G., Watal, A., Rai, P. K., Rai, D. K., Sharma, G., and Sharma, B. (2013). Biomedical applications of nano-antioxidant. Methods Mol. Biol. 1028, 147-151. doi: 10.1007/978-1-62703-475-3_9

Wu, Y. R., Choi, H. J., Kang, Y. G., Kim, J. K., and Shin, J. W. (2017). In vitro study on anti-inflammatory effects of epigallocatechin-3-gallate-loaded nano- and microscale particles. Int. J. Nanomed. 12, 7007-7013. doi: 10.2147/IJN.S146296

Xia, N., Daiber, A., Förstermann, U., and Li, H. (2017). Antioxidant effects of resveratrol in the cardiovascular system. Br. J. Pharmacol. 174, 1633-1646. doi: $10.1111 /$ bph.13492

$\mathrm{Xu}, \mathrm{D}$., Hu, M. J., Wang, Y. Q., and Cui, Y. L. (2019). Antioxidant activities of quercetin and its complexes for medicinal application. Molecules 24:E1123. doi: 10.3390/molecules24061123

Xu, D. P., Li, Y., Meng, X., Zhou, T., Zhou, Y., and Zheng, J. (2017). Natural antioxidants in foods and medicinal plants: extraction, assessment and resources. Int. J. Mol. Sci. 18:E96. doi: 10.3390/ijms18010096

Xu, H., Jia, F., Singh, P. K., Ruan, S., Zhang, H., and Li, X. (2016). Synergistic anti-glioma effect of a coloaded nano-drug delivery system. Int. J. Nanomed. 12, 29-40. doi: 10.2147/IJN.S116367

Xue, M., Yang, M. X., Zhang, W., Li, X. M., Gao, D. H., Ou, Z. M., et al. (2013). Characterization, pharmacokinetics, and hypoglycemic effect of berberine loaded solid lipid nanoparticles. Int. J. Nanomed. 8, 4677-4687. doi: $10.2147 / \mathrm{IJN} . S 51262$

Xue, M., Zhang, L., Yang, M. X., Zhang, W., Li, X. M., Ou, Z. M., et al. (2015). Berberine-loaded solid lipid nanoparticles are concentrated in the liver and ameliorate hepatosteatosis in $\mathrm{db} / \mathrm{db}$ mice. Int. J. Nanomed. 10, 5049-5057. doi: $10.2147 / I J N . S 84565$

Yabluchanskiy, A., Ungvari, Z., Csiszar, A., and Tarantini, S. (2018). Advances and challenges in geroscience research: an update. Physiol. Int. 105, 298-308. doi: $10.1556 / 2060.105 .2018 .4 .32$
Yan, J., Wang, Y., Zhang, X., Liu, S., Tian, C., and Wang, H. (2016). Targeted nanomedicine for prostate cancer therapy: docetaxel and curcumin co-encapsulated lipid-polymer hybrid nanoparticles for the enhanced anti-tumor activity in vitro and in vivo. Drug Deliv. 23, 1757-1762. doi: 10.3109/10717544.2015.1069423

Yang, K. Y., Lin, L. C., Tseng, T. Y., Wang, S. C., and Tsai, T. H. (2007). Oral bioavailability of curcumin in rat and the herbal analysis from Curcuma longa by LC-MS/MS. J. Chromatogr. B Analyt. Technol. Biomed. Life Sci. 853, 183-189 doi: 10.1016/j.jchromb.2007.03.010

Yang, X., Li, Y., Li, Y., Ren, X., Zhang, X., Hu, D., et al. (2017). Oxidative stressmediated atherosclerosis: mechanisms and therapies. Front. Physiol. 8:600. doi: 10.3389/fphys.2017.00600

Yang, X., Li, Z., Wang, N., Li, L., Song, L., He, T., et al. (2015). Curcuminencapsulated polymeric micelles suppress the development of colon cancer in vitro and in vivo. Sci. Rep. 5:10322. doi: 10.1038/srep10322

Yaribeygi, H., Farrokhi, F. R., Butler, A. E., and Sahebkar, A. (2019). Insulin resistance: review of the underlying molecular mechanisms. J. Cell. Physiol. 234, 8152-8161. doi: $10.1002 / \mathrm{jcp} .27603$

Yusuf, M., Khan, M., Khan, R. A., and Ahmed, B. (2012). Preparation, characterization, in vivo and biochemical evaluation of brain targeted Piperine solid lipid nanoparticles in an experimentally induced Alzheimer's disease model. J. Drug Target 21, 300-311. doi: 10.3109/1061186X.2012. 747529

Zhang, D., Zhang, J., Zeng, J., Li, Z., Zuo, H., Huang, C., et al. (2019). Nanogold loaded with resveratrol enhance the anti-hepatoma effect of resveratrol in vitro and in vivo. J. Biomed. Nanotechnol. 15, 288-300. doi: 10.1166/jbn. 2019.2682

Zhang, G., and Zhang, J. (2018). Enhanced oral bioavailability of EGCG using $\mathrm{pH}$-sensitive polymeric nanoparticles: characterization and in vivo investigation on nephrotic syndrome rats. Drug Des. Devel. Ther. 12, 2509-2518. doi: 10.2147/DDDT.S172919

Zhang, X. Y., and Zhang, P. Y. (2017). Polymersomes in nanomedicine - a review. Curr. Med. Chem. 13, 124-129. doi: 10.2174/1573413712666161018144519

Zheng, X., Zhang, F., Shao, D., Zhang, Z., Cui, L., Zhang, J., et al. (2018). Gramscale production of carrier-free fluorescent berberine microrods for selective liver cancer therapy. Biofactors 44, 496-502. doi: 10.1002/biof.1450

Zhou, Y., Du, J., Wang, L., and Wang, Y. (2017). Nanocrystals technology for improving bioavailability of poorly soluble drugs: a mini-review. J. Nanosci. Nanotechnol. 17, 18-28. doi: 10.1166/jnn.2017.13108

Zhu, B., Yu, L., and Yue, Q. (2017). Co-delivery of vincristine and quercetin by nanocarriers for lymphoma combination chemotherapy. Biomed Pharmacother. 91, 287-294. doi: 10.1016/j.biopha.2017.02.112

Zuberek, M., and Grzelak, A. (2018). Nanoparticles-caused oxidative imbalance. Adv. Exp. Med. Biol. 1048, 85-98. doi: 10.1007/978-3-319-72041-8_6

Zuo, L., Prather, E. R., Stetskiv, M., Garrison, D. E., Meade, J. R., Peace, T. I., et al. (2019). Inflammaging and oxidative stress in human diseases: from molecular mechanisms to novel treatments. Int. J. Mol. Sci. 20:E4472. doi: $10.3390 / \mathrm{ijms} 20184472$

Conflict of Interest: The authors declare that the research was conducted in the absence of any commercial or financial relationships that could be construed as a potential conflict of interest.

Copyright (c) 2020 Vaiserman, Koliada, Zayachkivska and Lushchak. This is an openaccess article distributed under the terms of the Creative Commons Attribution License (CC BY). The use, distribution or reproduction in other forums is permitted, provided the original author(s) and the copyright owner(s) are credited and that the original publication in this journal is cited, in accordance with accepted academic practice. No use, distribution or reproduction is permitted which does not comply with these terms. 